\title{
HYDROGEN IS NEUROPROTECTIVE AND PRESERVES NEUROVASCULAR REACTIVITY FOLLOWING ASPHYXIA IN NEWBORN PIGS
}

\author{
By \\ Orsolya Oláh \\ A Thesis for the Degree of \\ DOCTOR OF PHILOSOPHY \\ (Ph.D.)
}

In the Department of Physiology, Faculty of Medicine, University of Szeged

Consultant: Ferenc Domoki, M.D., Ph.D.

Doctoral School of Basic Medicine

2015

Szeged 


\section{PUBLICATIONS RELATED TO THE SUBJECT OF THE THESIS}

I. Domoki F, Olah O, Zimmermann A, Nemeth I, Toth-Szuki V, Hugyecz M, Temesvári P and Bari F (2010) Hydrogen is neuroprotective and preserves cerebrovascular reactivity in asphyxiated newborn pigs. Pediatr Res 68: 387-392.

IF: 2,803

II. Olah O, Nemeth I, Toth-Szuki V, Bari F and Domoki F (2012) Regional Differences in the Neuronal Expression of Cyclooxygenase-2 (COX-2) in the Newborn Pig Brain. Acta Histochem Cytochem 45: 187-192.

IF: 1,48

III. Domoki F, Zolei D, Olah O, Toth-Szuki V, Hopp B, Bari F and Smausz T (2012) Evaluation of laser-speckle contrast image analysis techniques in the cortical microcirculation of piglets. Microvasc Res 83: 311-317.

IF: 2,929

IV. Olah O, Toth-Szuki V, Temesvari P, Bari F and Domoki F (2013) Delayed neurovascular dysfunction is alleviated by hydrogen in asphyxiated newborn pigs. Neonatology 104:79-86.

IF: 2,573 


\section{Table of contents}

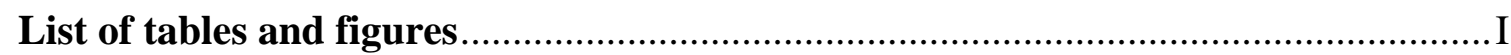

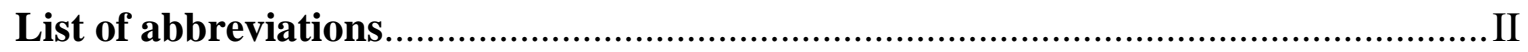

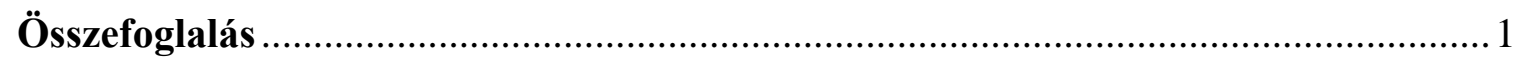

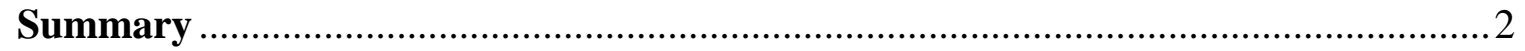

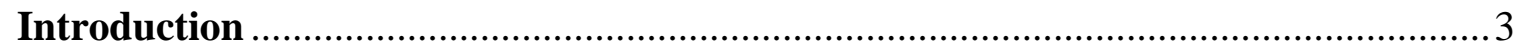

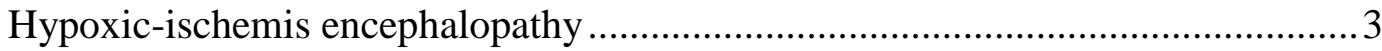

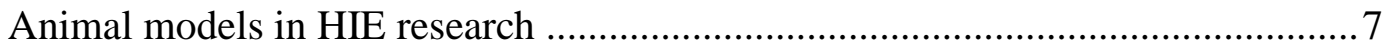

The concept of ,neurovascular unit” in neonatal research ....................................

Neuroprotective treatment perspectives .................................................... 11

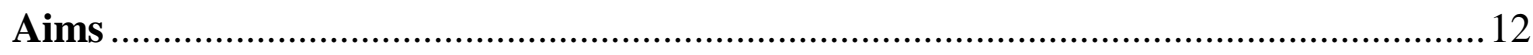

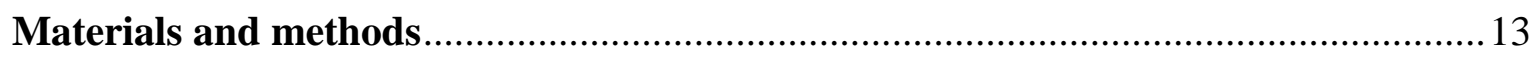

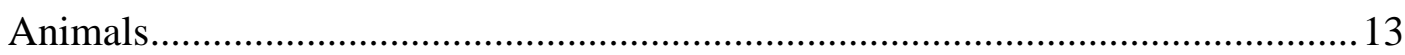

Experimental groups to study the effects of molecular H2 on CR ........................ 13

Animal preparation and birth asphyxia ..................................................... 14

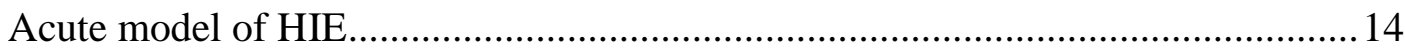

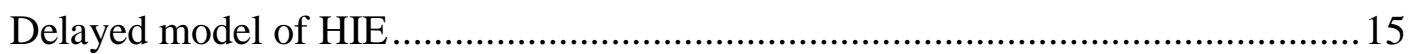

Closed cranial window/intravital videomycroscopy and determination of CR.......16

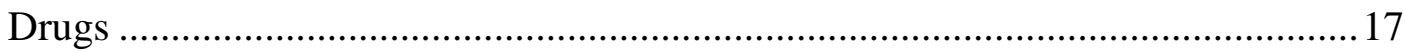

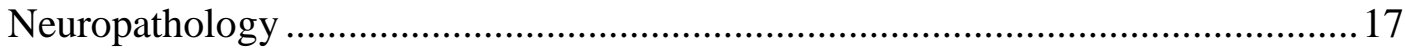

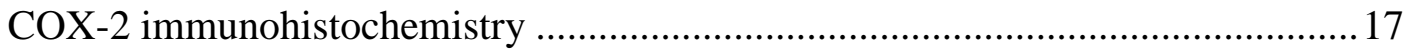

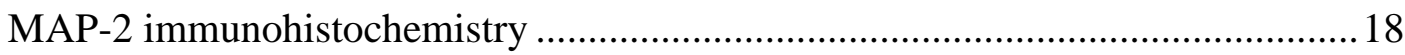

Laser speckle contrast analysis (LASCA) technique ...........................................19

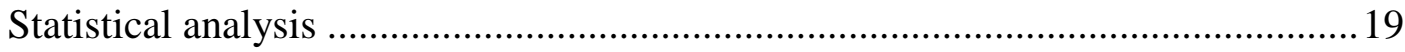

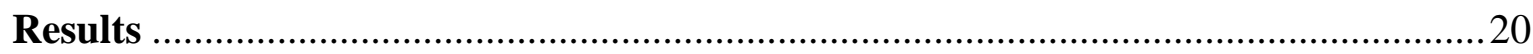

Acute effects of asphyxia on vital parameters and CR......................................20

Neuropathology - acute neuronal changes .................................................. 22 


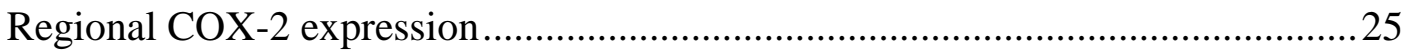

Delayed changes in vital parameters and CR following birth asphyxia.................28

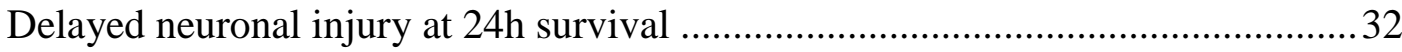

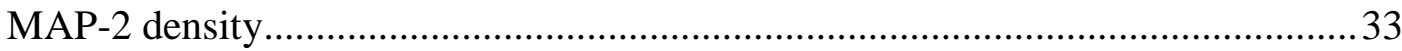

LSI/LASCA studies ont he cortical microcirculation ...........................................34

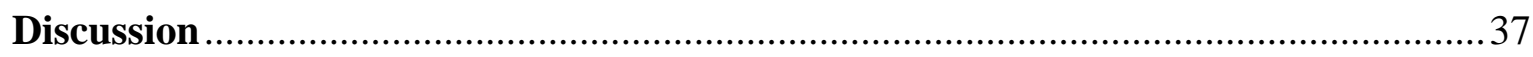

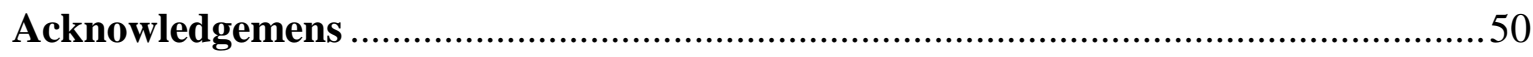

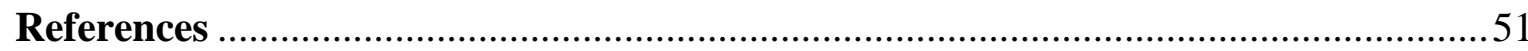




\section{List of tables and figures}

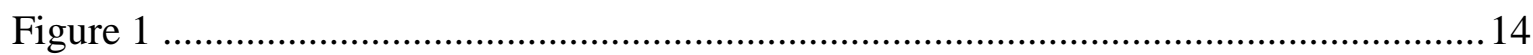

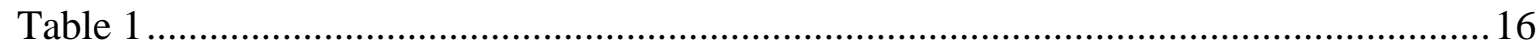

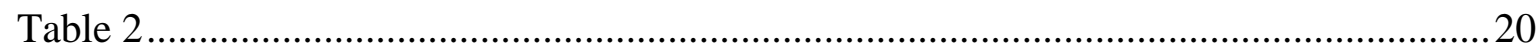

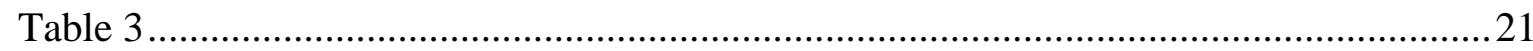

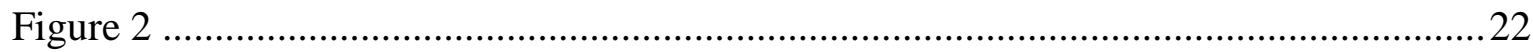

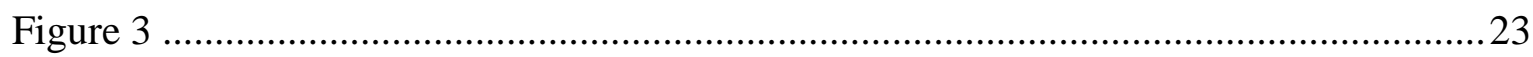

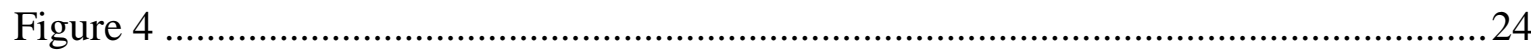

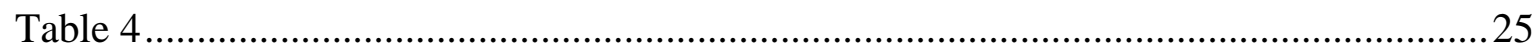

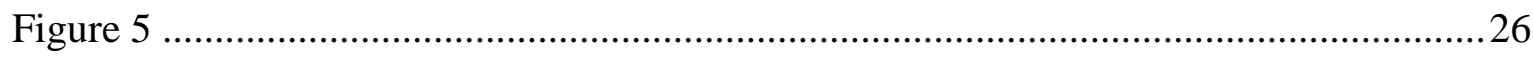

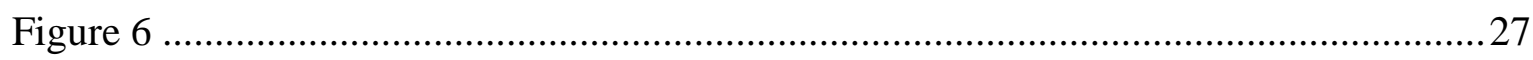

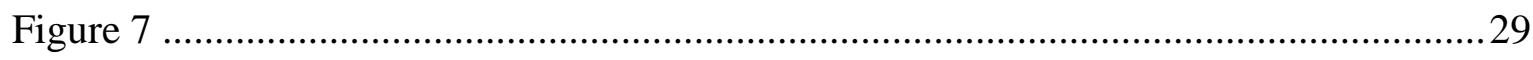

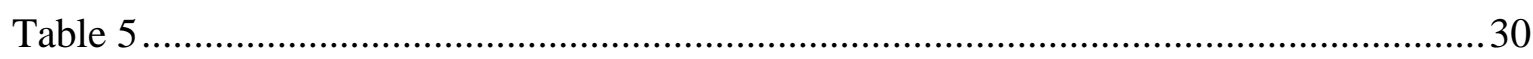

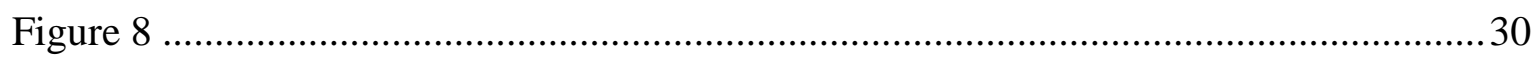

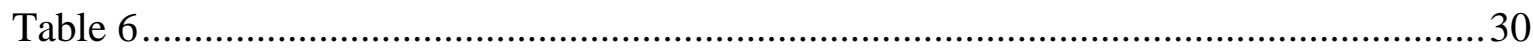

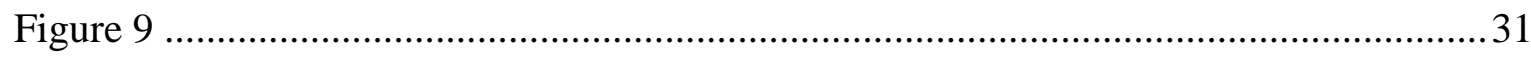

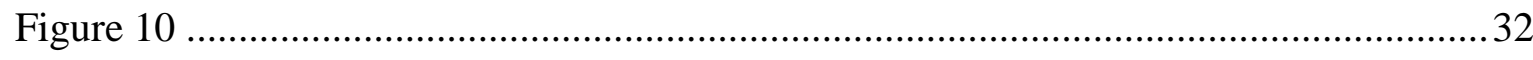

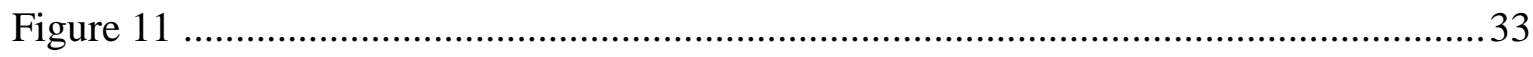

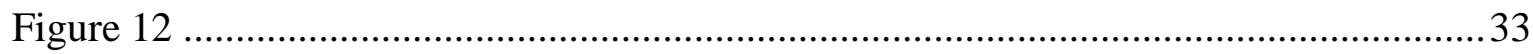

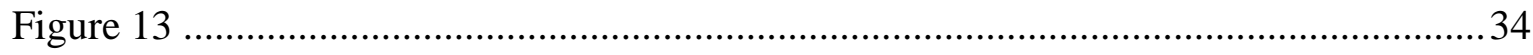

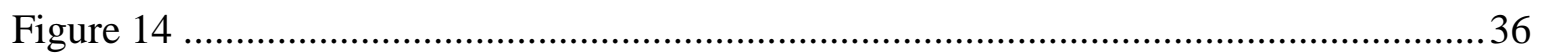




\section{List of abbreviations}

\begin{tabular}{|c|c|}
\hline $\mathrm{A} / \mathrm{R}$ & asphyxia/revetilation \\
\hline AA & arachidonic acid \\
\hline $\mathrm{aCSF}$ & artificial cerebrospinal fluid \\
\hline $\mathrm{aEEG}$ & amplitude-integrated electroencephalography \\
\hline ANOVA & analysis of variance \\
\hline BBB & blood brain barrier \\
\hline $\mathrm{CBF}$ & cerebral blood flow \\
\hline $\mathrm{CCD}$ & charge-coupled device \\
\hline CNS & central nervous system \\
\hline $\mathrm{CoBF}$ & cortical blood flow \\
\hline $\mathrm{CoBF}$ & cortical blood flow \\
\hline COX & cyclooxygenase \\
\hline $\mathrm{COX}-2$ & cyclooxygenase- 2 \\
\hline $\mathrm{CR}$ & cerebrovascular reactivity \\
\hline CSF & cerebrospinal fluid \\
\hline DAB & 3,3'-diaminobenzidine \\
\hline DNA & dezoxyribonucleic acid \\
\hline ECG & electrocartdiography \\
\hline EEG & electroencephalography \\
\hline GABA & gama-amino-butiric-acid \\
\hline $\mathrm{H} / \mathrm{E}$ & hematoxylin/eosin \\
\hline $\mathrm{H}_{2}$ & hydrogen \\
\hline $\mathrm{H}_{2} \mathrm{O}_{2}$ & hydrogen peroxide \\
\hline $\mathrm{H}_{2}-\mathrm{RA}$ & H2-supplemented room air \\
\hline
\end{tabular}




\begin{tabular}{|c|c|}
\hline HIE & hypoxic-ischemic encephalopathy \\
\hline HPC & hippocampus \\
\hline ICU & intensive care unit \\
\hline ip. & intraperitoneal \\
\hline iv. & intravenuous \\
\hline LASCA & laser speckle contrast analysis \\
\hline LDF & laser-Doppler flowmetry \\
\hline LSI & laser-speckle imaging \\
\hline MABP & mean arteriolar blood pressure \\
\hline MAP-2 & microtubule associated protein-2 \\
\hline MRI & magnetic resonance imaging \\
\hline NA & noradrenalin \\
\hline NMDA & N-methyl-D-aspartate \\
\hline NO & nitrogen monoxide \\
\hline NVU & neurovascular unit \\
\hline PAD & pial arteriolar diameter \\
\hline $\mathrm{pCO}_{2}$ & partial pressure of $\mathrm{CO}_{2}$ \\
\hline $\mathrm{pO}_{2}$ & partial pressure of $\mathrm{O}_{2}$ \\
\hline RA & room air \\
\hline ROS & reactive oxygen species \\
\hline SEM & standard error of mean \\
\hline SHAM & sham-operated control \\
\hline SNP & sodium-nitroprusside \\
\hline
\end{tabular}




\section{Összefoglalás}

A perinatális aszfixia a csecsemő halálát, vagy a központi idegrendszer (KIR) maradandó károsodását: ún. hipoxiás-iszkémiás enkefalopátiát (HIE) okozhat. A HIE évente, világszerte mintegy egymillió csecsemőt érint, de súlyos társadalmi és gazdasági következményei ellenére, az első klinikailag igazolt neuroprotektív terápia, - a mérsékelt teljes test hipotermia - csak az elmúlt években került szélesebb körben alkalmazásra. Az aszfixiás újszülött újraélesztése szinte valamennyi esetben a lélegeztetés megindításával kezdődik, ezért a lélegeztetésre felhasznált gázkeverékbe kevert, neuroprotektív hatású gázok a károsodásokat önmagukban is mérsékelhetnék, a hipotermiával kombinálva pedig fokozhatnák annak hatékonyságát. Például a molekuláris hidrogén ideális terápiás szer lehetne hidroxil és peroxinitrit gyökökre szelektív antioxidáns tulajdonságánál fogva.

A HIE vizsgálatára több állatkísérletes modell áll rendelkezésre. Szegedi laboratóriumunkban a HIE vizsgálatára elfogadott girenkefál fajt, az újszülött malacot alkalmaztuk. A HIE patomechanizmusában jelentős szerepet játszhat az ún. neurovaszkuláris egység funkciókárosodása, mely felelős a neuronok metabolikus igényeinek biztosításáért. Ezért a molekuláris hidrogén neuroprotektív hatásának elemzéséhez a neuropatológiai vizsgálatok mellett a neurovaszkuláris egység integritását jelző stimulusokkal szembeni cerebrovaszkuláris reaktivitást (CR) határoztuk meg mind az inzultust követő túlélés akut (1-4 óra, $n=31$ ) és szubakut (24 óra, $n=27$ ) fázisában. Új kísérleti eredményeink közül kiemelendő az a korábban nem ismert jelenség, hogy aszfixiát követően a neurovaszkuláris diszfunkció átmeneti javulás után újra súlyosan károsodik a szubakut időszakban. A molekuláris hidrogén, noha önmagában nem befolyásolja a CR-t ill. az agykérgi véráramlást, azonban aszfixiát követően egyaránt mérsékli mind a neurovaszkuláris egység funkciójának, mind a KIR idegsejtjeinek károsodását.

Eredményeink összhangban vannak a hidrogén antioxidáns hatásmechanizmusával, hiszen a neurovaszkuláris egység károsodásáért jelentős részben a reoxigenizációs periódus során megnövekedett reaktív oxigéngyök termelődés felelős. Eredményeink arra isrámutatnak, hogy az aszfixiát követő korai reoxigenizációs periódusban alkalmazott molekuláris hidrogén nemcsak rövid, hanem hosszabb távon is képes javítani a neuronálisvaszkuláris funkciót, továbbá felveti további preklinikai vizsgálatok szükségességét. A molekuláris hidrogén további vizsgálatának jogosultságát alátámasztja egyszerü előállíthatósága, adagolhatósága és kedvező farmakokinetikai tulajdonságai. 


\section{Summary}

Perinatal asphyxia can elicit mortality or severe disability in the survivors called hypoxic-ischemic encephalopathy (HIE) in term infants. HIE yearly affects around one million babies worldwide. In contrast to the severe impact of HIE on the society and on the health care budget, the first effective neuroprotective therapy, mild whole-body hypothermia, has only recently been introduced into broader clinical practice. The resuscitation efforts in asphyxiated infants start invariably with adequate mechanical ventilation. The gas mixture used for artificial ventilation could be used to deliver possibly neuroprotective gases to reduce CNS damage, and to perhaps augment the efficacy of hypothermia. For instance, molecular hydrogen could be an ideal therapeutic agent, as it has recently been shown to exert selective antioxidant properties against hydroxyl and peroxynitrite radicals.

There are several animal models to study HIE pathology.. In our Szeged laboratory, a widely-used gyrencephalic large animal model of HIE, the newborn piglet has been utilized. Dysfunction of the so-called neurovascular unit - that is responsible for meeting the metabolic demands of neurons - may play an important role in the pathomechanism of HIE. Therefore, to assess the putative neuroprotective effects of molecular hydrogen, beside neuropathology we also determined CR to stimuli indicating neurovascular unit integrity both in the acute (1-4 $\mathrm{h}, \mathrm{n}=31)$ and the subacute ( $24 \mathrm{~h}, \mathrm{n}=27)$ phase of survival after asphyxia. We would like to highlight the novel observation from our results that after an initial recovery at the end of the acute period, a second delayed neurovascular unit dysfunction develops in the subacute phase. The molecular hydrogen gas per se did not affect CR or cortical perfusion, but preserved neurovascular unit function and diminished neuronal damage in the CNS after asphyxia.

Our results are in accordance with the antioxidant mechanism of molecular hydrogen actions, since neurovascular unit dysfunction has been previously shown to be triggered by elevated levels of reactive oxygen species during reoxygenation. Our data suggest that molecular hydrogen administered in the early reoxygenation can alleviate not only the acute but also the delayed phase of neurovascular dysfunction demanding further preclinical research. The importance of further research on molecular hydrogen is also substantiated by its other appealing features concerning its medical use: it is inexpensive, simple to produce and to administer, and has ideal pharmacokinetics. 


\section{Introduction}

\section{Hypoxic-ischemic encephalopathy}

Perinatal asphyxia, more appropriately the subsequently developing hypoxic-ischemic encephalopathy (HIE) is a severe condition in neonatology, which can cause significant mortality and long-term morbidity. HIE is characterized by clinical and laboratory evidence of brain injury caused by asphyxia. Despite the recent technical developments in monitoring technologies, most often the exact timing and the underlying cause of HIE remains unknown. The most common primary physiological processes that lead to brain hypoxia and ischemia, thus causes HIE are systemic hypoxemia/hypercapnia, and/or reduced cerebral blood flow $(\mathrm{CBF})[1-3]$.

In most developed countries, the incidence of severe perinatal asphyxia and the subsequent HIE is around 1-8 cases per 1000 births. The incidence of HIE in countries with limited resources is higher, however precise numbers and figures are not available. Birth asphyxia is responsible for $23 \%$ of all neonatal deaths worldwide, and taking into consideration its $8 \%$ contribution of the yearly 10.6 million deaths of children younger than five years, HIE is the fifth largest cause of death in this age group [4, 5]. Aside from the significant responsibility in pediatric mortality, more than a million children surviving birth asphyxia will suffer from cerebral palsy, mental retardation, epilepsy, learning difficulties, and other disabilities [6].

The preconceptual and antepartum risk factors of HIE are still unclear, although it seems that insulin-dependent diabetes mellitus, thyroid disease, fertility treatments, severe preeclampsia, placental abruption and intrauterine growth restriction may have significant impact on the incidence of birth asphyxia. The intrapartum events, such as cord prolapse, maternal pyrexia and instrumentation were responsible for HIE just in 5-15\% of cases $[7,8]$.

According to clinical symptoms and laboratory signs, stages of increasing severity can be distinguished (see the Sarnat Staging System [9]). In mild HIE, transient neurological and behavioural abnormalities can be observed (eg. increased muscle tone, poor feeding, excessive crying or sleepiness). All symptoms should normalize by the end of the first week of life. Infants with mild asphyxia tend to be free from serious central nervous system complications. In moderately severe HIE, significant lesions can be observed, such as seizures in the first 24 hours of life, lethargy, hypotonia and diminished deep tendon reflexes, 
periods of apnea and absent reflexes (grasping, Moro etc.). Recovery usually takes place in 12 weeks, with a better long-term outcome. $30-50 \%$ of these infants have serious long-term complications, and 10-20\% show minor neurological morbidities. In severe HIE, generalized seizures occur early after the injury, and may be resistant to any conventional therapy. The frequency of seizures may progress during the first 1-2 days. As the injury progresses the electroencephalogram (EEG) becomes isoelectric or shows burst suppression pattern and the symptoms of cerebral edema appear. In addition, other severe neurological signs can appear; stupor or coma, lack of neonatal reflexes (eg. swallowing, Moro, sucking, grasping), generalized hypotonia and depressed deep tendon reflexes, irregular breathing, fixed or poorly reactive pupils, accompanied by the instability of the cerebrovascular circulation and thus oxygenation. In severe birth asphyxia the mortality rate can be as high as $25-50 \%$, but $80 \%$ of the survivors will develop severe, $20 \%$ more moderately severe complications, and as few as only $10 \%$ will show nearly complete recovery. The deaths mostly occur in the first week of life due to multiple organ failure, or later through severe neurological disabilities due to aspiration pneumonia or systemic infections [10].

Brain hypoxia and ischemia, and the subsequently developing HIE is caused by systemic hypoxemia and/or reduced CBF [1-3]. The severity of the final neuronal damage is determined by the initial insult aggravated by the effects of reperfusion injury and delayed neuronal cell death [2]. It is also observed that the areas primarily affected contain either the highest concentration of N-methyl-D-aspartate (NMDA) receptors or where active myelination takes place. In severe forms of asphyxia-induced brain damage, the injury is confined mostly to the deep gray matter (eg. putamen, ventrolateral thalamus, hippocampus, dorsal brainstem, and lateral geniculate nucleus) and the perirolandic cortex. Less severe or partial insult often results in the so-called watershed injury, injury limited to the intervascular boundaries areas [10]. Injuries predominant to the basal ganglia or thalamus are associated with unfavourable neurological outcome when compared with infants with white matter predominant pattern injury [11].

The diagnosis of HIE is made based on the history, physical and neurological examinations, and laboratory evidence. The laboratory tests are performed to assess the severity of the neuronal injury and to monitor the status of the systemic organs, also to avoid hyperoxia and hypoxia as well as hypercapnia and hypocapnia. The most comprehensive status can be obtained by using brain MRI, which is the best imaging modality for the diagnosis and follow-up of infants with moderate or severe HIE [12]. 
Multichannel electroencephalography (EEG) is also an integral part of the evaluation of infants diagnosed with HIE. It can be used to assess the severity of the injury and also to evaluate the subclinical electrographic seizures especially for infants on assisted ventilation requiring sedation or paralysis [13]. Different EEG characteristics can be associated with abnormal outcome (eg. low background amplitude, long interburst interval, electrographic seizures, and long term absence of sleep-wake cycling). Albeit EEG recordings can provide good approximation to predict neurological outcome, the evaluation requires a trained specialist, and it is often hardly manageable at the bedside.

The other useful tool in monitoring brain function in moderate-to-severe cases of HIE is the single-channel amplitude-integrated electroencephalography (aEEG). The aEEG is a noninvasive cerebral function monitor method with the possibility of immediate evaluation that can replace the bedside long-term EEG monitoring. Several studies have shown that aEEG performed within a few hours of birth can help in evaluation of severity of HIE [14]. Although normal aEEG recording may not necessarily mean that the brain is intact, a severe or moderately severe aEEG abnormality refers to brain injury and poor outcome. The potential of recovery of the abnormal aEEG within the first 24 hours is usually associated with favorable outcome [15].

The treatment of HIE in the initial period until recently was largely supportive, limited to resuscitation and stabilization. The following care focused on adequate ventilation and perfusion, fluid management, avoidance of hypoglycaemia and hyperthermia. These interventions mainly aimed to avoid further brain injuries but did not offer much hope for neuroprotection.

The gas used for artificial ventilation during resuscitation received a lot of attention in the last decade. Several clinical trials indicate that room air resuscitation for infants with perinatal asphyxia is as, or more effective as the resuscitation with $100 \%$ oxygen. In addition, room air ventilation provides less oxidative stress by reducing the amount of produced ROS [16]. Most infants with severe HIE need ventilation during the first days of life. The role of mechanical ventilation is to maintain the physiological ranges of blood gases and acid-base status; to prevent hypoxia, hyperoxia, hypercapnia and hypocapnia. Animal data suggest that hypercapnia may be neuroprotective, however no such evidence is available in newborn. In contrast, hypocapnia may lead to brain hypoperfusion, thus may be associated with worse neurodevelopmental outcome $[17,18]$. 
Fluid therapy should aim to keep glucose levels stable and ionic homeostasis should be maintained in physiological range. Both hypoglycemia and hyperglycemia may accentuate brain damage [19].

It has been shown that the body temperature critically affects the outcomes in infants with moderate-to-severe HIE. Hyperthermia may be associated with a risk of increase of death or severe disability. For every $1{ }^{\circ} \mathrm{C}$ increase in the mean of the highest quartile of skin or esophageal temperature the risk of death or disability was increased 4-fold [20]. In contrast, experimental data have shown that mild hypothermia applied in the initial period of injury (no later than 6 hours) is neuroprotective. The possible neuroprotective mechanisms possibly include the reduced metabolic rate, the decreased excitatory transmitter release, reduced apoptosis, and reduced vascular permeability preventing edema, and disruptions of other blood-brain barrier functions [21, 22]. Recently, the Total Body Hypothermia for Neonatal Encephalopathy Trial study group, and some other randomized controlled trials have shown that moderate whole-body hypothermia improves outcome in full-term infants by decreasing the incidence of severe neurodevelopmental deficits [23-27]. In this group of patients, the cooling must begin within 6 hours of injury and maintained for 48-72 hours. The greater the severity of the injury, the longer duration of hypothermia is needed for optimal neuroprotection. It has been proved that applied mild hypothermia caused better outcome two years after the hypoxic-ischemic insult [23, 28, 29], likewise better neurodevelopmental outcome was shown in school-age patient treated with hypothermia [30]. Thus, body cooling recently has become standard care in infants suffered from perinatal asphyxia. 


\section{Animal models in HIE research}

Several research groups are currently investigating other possible neuroprotective strategies in order to determine whether these alone or in combination with hypothermia can cause favourable outcome after HIE [31-33]. Although these investigations involve a broad spectrum of promising avenues, it should be emphasized that a clinical trial in neonates requires special attention because of possible implications, ethical issues and financial concerns. For this reason animal models have significant role in seeking suitable therapies that can increase survival and attenuate neurological deficits.

There are numerous reviews providing information regarding the variety, frequency of use, and relative appropriateness of both large and small animal models to the study of brain injury in the perinatal period [34-38], albeit no model is perfect in reflecting the complexity of the human brain and pathology of HIE. Potential neuroprotective therapies after birth asphyxia must be evaluated in newborn animals, because on one hand the younger animals have relatively greater resistance to hypoxic-ischemic injury, on the other hand, neurons are more vulnerable to injury $[39,40]$. Every animal model developed for the study of neonatal hypoxic-ischemic injury has to pay attention to the species-specific properties of the chosen species. Major attributes having significant impact on the interpretation of results originating from an animal model are; 1) how mature is the brain at birth (or at the age of experiment), and how does this correlate with a term human infant, 2) what are the species-specific characteristics of $\mathrm{CBF}$ that would impact on the experimental model, 3) what are the important cerebral metabolic considerations, 4) does the model truly mimic the human disease or is it more useful in discovering general cellular mechanisms of injury and neuroprotection [41].

By far the most commonly used robust and productive rodent model is the postnatal day 7 rat developed in 1981 by Vannucci et al. [42] that is used in high number of studies due to the availability of large number of animals [36, 37, 43, 44]. The rat model has been well characterized over the years, with respect to cerebral metabolic perturbations, neuropathology, and attempts at neuroprotection $[45,46]$. This model is particularly useful for screening new treatment strategies, but it cannot be used in studies where physiologic monitoring is important. Essential differences may exist in the pathomechanisms, shown for example by the effect of hyperglycemia during hypoxia-ischemia: neuronal injury is not enhanced by an increased blood glucose in rodents, in contrast to the human infants or other large animal 
models such as newborn pig or adolescent monkey, in which hyperglycemia has detrimental effects [47].

With the increase in availability of transgenic mice, the Vannucci model was adapted also to the mouse [48]. Murine models have provided remarkable insights of cellular patophysiological mechanisms, due to the short generation times, inexpensive breeding and keeping, and the utilization of genetic engineering techniques. Nevertheless the murine models also have numerous disadvantages; there are significant differences in brain size and development that aggravate the direct comparison of results between mice and humans [49].

One of the effectively used large animal species in HIE studies is the fetal sheep exposed to maternal hypoxemia [50, 51]. Studies elucidated the cerebral and systemic metabolic effects of acute and chronic cord occlusion and term asphyxia in the sheep fetus [50]. Despite the obtained neurophysiological data the model has also major disadvantages; the pregnant ewes are large and expensive and the surviving lambs show surprisingly little clinical evidence of chronic brain injury.

Near-term fetal rabbits have also been used to mimic placental insufficiency, persistent hypertonia, cerebral palsy and biochemical changes [52-54]. In this model, the preterm rabbit fetuses are exposed to sustained placental insufficiency that is monitored with diffusionweighted imaging. These studies can help in the development of therapeutic interventions, although, not all the neurological changes are identical to that observed during HIE in human infants.

Presumably the most appropriate large animal model in studying perinatal injuries would be a primate model. The clinical and pathologic changes produced in term monkeys by various degrees of asphyxia closely resemble the changes observed in asphyxiated infants [55, 56]. Further advantages of primate models, that anatomical characteristics and the pace of intrauterine development are nearly identical, furthermore the design of management of injuries reflects the human neonatal intensive care unit [56]. Thus, the clinical and pathological findings are remarkably similar to those that have been noted in human infants, rendering this model of potentially highly relevant, particularly for neuroprotective drug trials for birth asphyxia before a clinical trial. Despite of all benefits listed above for primate models, the use of nonhuman primates for the study of HIE like for other neurological diseases is clearly not applicable at the moment because of the cost in time and resources 
necessary to develop and use these models combined with ethical considerations and rebuttal from animal rights organisations.

The newborn pig has numerous anatomical and physiological similarities to human infants that allow translational conclusions from the experimental findings to clinical settings. Similarities in structure and function between pigs and human beings include size, feeding patterns, gastrointestinal system, endocrine system, immune system, pulmonary vascular bed structure, coronary artery distribution, respiratory rates, tidal volumes, neurological structure and social behaviours [57]. In addition, there are genetic similarities, the swine proteins have a relatively high sequence homology to humans, $60 \%$ compared to the $40 \%$ sequence homology between rodents and humans. The pig chromosomal structure has higher similarity to humans than those of mouse, rat, dog, cat, horse and cattle [58]. It is especially relevant for neonatal research that the physiological properties of newborn piglets, such as birth weight, brain developmental stage, and cerebrovascular physiology at birth are very similar to term infants. Due to these similarities, the newborn piglet has been established as a valuable experimental tool to study the pathophysiology of neonatal HIE and to test promising new therapeutic approaches [59]. In the piglet model, HIE causes damage very similar to the pattern of brain injury found in human that have experienced hypoxia-ischemia [60].

In our laboratory, the newborn piglet model has long been used to study the morphology and functional responses of cerebrovascular system in physiologic and pathologic conditions [61-67]. We and others have repeatedly shown that hypoxic-ischemic stress in newborn piglets severely attenuated CR to various so called "hypoxia-ischemia sensitive" stimuli determined in pial arterioles 1 hour after the insult [61, 64, 68-70]. The attenuated CR showed spontaneous recovery, and it appeared intact as early as 4 hours after the ischemic insult $[61,62,68,70]$. The impairment of CR is concomitant with neuronal damage, and glial activation [71].

\section{The concept of "neurovascular unit" in neonatal research}

Regulation of CBF is highly dependent on the morphological and functional interaction of neurons, astrocytes and various cerebromicrovascular cells [72, 73]. This 'interaction between circulating blood elements and the blood vessel wall, extracellular matrix, glia, and neurons' gave the initial description of neurovascular unit (Report of the Stroke Progress Research Group, 2002). The anatomy and organization of the neurovascular unit incorporates the specialized endothelium in cerebral microvessels, sealed by tight junctions and isolated 
from the surrounding brain cells by basement membrane, the pericytes enveloped in the basement membrane, astrocytic endfeet covering more than $98 \%$ of the vascular wall, and perivascular neurons. The astrocytes communicate with neurons creating the link for endothelial-neuronal coupling, and matching blood flow to metabolic demand by neurons [74]. The cellular anatomy of the neurovascular unit has been extended with inflammatory cells that interact with the luminal site of brain endothelium, and perivascular macrophages and microglia participating in innate immune responses [75]. Besides regulating the local blood flow, the neurovascular unit has significant roles in regulation of blood-brain barrier permeability and transport, neuroimmune responses, and angiogenesis - neurovascular remodelling [76]. Tissue hypoxia is an initial trigger of pathophysiological changes in the neurovascular unit. The hypoxia associated increase in blood-brain barrier permeability, water and ion redistribution, and cerebrovascular oxidative stress create secondary injury to the neurovascular unit $[77,78]$. The contribution of neurovascular unit dysfunction to the development of HIE so far has received little attention, although its role in neuronal injury has been recently widely recognized in adult stroke [79].

The function of the neurovascular unit can be assessed by measuring CR. During CR testing, the system is challenged with a vasoactive stimulus and the response is being observed and recorded. In the literature, CR to three different types of vasodilatory stimuli has been most often determined: 1) transient reduction in mean arterial blood pressure [80, 81], 2) the administration (systemic or local) of a vasoactive chemical substance [82, 83], or an 3) an increase in carbon dioxide level [61].

In our laboratory, for CR determination two stimuli have been selected to test neurovascular unit integrity: hypercapnia induced by ventilation with carbon dioxide, and the topical application of NMDA. Hypercapnia causes dose-dependent pial arteriolar dilation in newborn pigs that is impaired by moderate-to severe hypoxic-ischemic insult [62, 68, 70, 84]. NMDA, a synthetic receptor-specific analogue of glutamate, is proved to be vasodilator in the cerebral circulation [82]. Similarly to carbon dioxide NMDA causes dose-dependent dilation on the pial arterioles and subsequent hyperaemia in piglets that involves the neuronal synthesis and vascular actions of $\mathrm{NO}[65,85,86]$. 


\section{Neuroprotective treatment perspectives}

As it has already been mentioned, currently only the moderate whole-body hypothermia is the only effective treatment of HIE, however, hypothermia alone is unable to provide full functional recovery in most patients. Therefore, further research to find new neuroprotective treatments is warranted. During the management of asphyxiated infants the reoxygenation of the tissues is a primary goal of resuscitation efforts; however, reoxygenation and reperfusion provide oxygen for the synthesis of ROS that can result in oxidative stress [87-91]. Moreover, ROS produced in the early reoxygenation period have been shown to be responsible for acute neurovascular unit dysfunction [92, 93]. Ventilation with pure oxygen has been shown to be detrimental in neonatal large animal models [94-96] and in clinical trials as well $[92,93]$. Resuscitation is now recommended with air to be supplemented with oxygen in infants with persistent central cyanosis [97]. However, the gas mixture used for resuscitation could perhaps be used to deliver neuroprotective agents to the brain.

Molecular hydrogen $\left(\mathrm{H}_{2}\right)$ has been shown to exert antioxidant properties with selectively scavenging the hydroxyl radical, the most aggressive ROS that is produced mostly in pathological conditions [98]. In addition to its putatively hydroxyl-radical selective antioxidant effect, $\mathrm{H}_{2}$ has other obvious advantages: it can penetrate biomembranes and diffuse into the mitochondria and nucleus - the sites of severe cellular oxidative damage. Furthermore, inhalation of low concentration of $\mathrm{H}_{2}$ gas has no known side effects. Due to these advantageous features of $\mathrm{H}_{2}$ treatment, the effects of molecular $\mathrm{H}_{2}$ administration has been widely tested in ROS-associated neuropathologic conditions in which the outcome can be greatly influenced by the rapid bioavailability of the neuroprotective drug in the brain. $\mathrm{H}_{2}$ was indeed neuroprotective against hypoxic/ischemic injury in adult and neonatal rats [98100] and also in a rat model of Parkinson's disease [101]. However, the possible protective effect of $\mathrm{H}_{2}$ against perinatal asphyxia previously has not been tested in a large animal model. 


\section{Aims}

In the Cerebrovascular Laboratory at the Department of Physiology, the newborn piglet model has been successfully used previously to study acute changes in CR to various vasoactive stimuli before and after (up to 4 hours) hypoxic/ischemic stress.

Therefore, we first wished to investigate in this acute piglet asphyxia model if 1) molecular $\mathrm{H}_{2}$ preserves $\mathrm{CR}$ to hypoxia/ischemia sensitive vasodilator stimuli and has neuroprotective effects. Additionally, we also assessed if 2) inhalation of $\mathrm{H}_{2}$-supplemented room air was safe to newborn pigs in a concentration applied to rodents previously; if 3) $\mathrm{H}_{2}$ supplemented ventilation per se affected cortical blood flow, the $\mathrm{CR}$ or the microscopic morphology of the brain in time control animals, and if 4) neuronal cyclooxygenase-2 expression - a sensitive indicator of neuronal cellular stress was affected by $\mathrm{H}_{2}$ ventilation.

The positive results and the limitations of these studies urged us to extend our observations to the $24 \mathrm{~h}$ survival time period. We introduced a new subacute piglet translational HIE model that aimed to parallel the early supportive care of HIE patients. In this new model, we wished to investigate if 5) neurovascular unit function was affected 24 hour after asphyxia, if 6) $\mathrm{H}_{2}$ modified CR to hypoxia/ischemia sensitive stimuli, if 7) $\mathrm{H}_{2}$ affected recovery of brain electrical activity after asphyxia, and if 8) $\mathrm{H}_{2}$-induced neuroprotection could be observed by histopathology.

The determination of $\mathrm{CR}$ has been traditionally assessed in our laboratory by measuring the diameter changes of pial arterioles. As part of a research collaboration, we were involved in the development and in vivo testing of a laser-speckle imager which allowed us to assess 9) the effect of pial arteriolar diameter changes on the perfusion changes in the cortical parenchyma thus validating our CR determinations on pial arterioles. 


\section{Materials and methods}

\section{Animals}

Newborn (1-2 days old, body weight: 1,5-2,5 kg) Large-White piglets of either sex $(\mathrm{n}=81)$ were obtained from a local company (Pigmark Ltd. Co., Szeged, Hungary) on the morning of the experiment. All experiments were approved by the Institution Animal Care and Use Committee of the University of Szeged.

\section{Experimental groups to study the effects of molecular $\mathrm{H}_{2}$ on $\mathrm{CR}$}

The animals were divided into 7 experimental groups (Figure 1.). The first set of experiments (groups 1-4) was designed to investigate the acute neurovascular changes of birth asphyxia and 4 hours of reventilation with room air (RA - $21 \% \mathrm{O}_{2}, 79 \% \mathrm{~N}_{2}$ ) or $\mathrm{H}_{2}-$ supplemented room air $\left(\mathrm{H}_{2}-\mathrm{RA}-2.1 \% \quad \mathrm{H}_{2} ; 21 \% \quad \mathrm{O}_{2} ; 76.9 \% \quad \mathrm{~N}_{2}\right)$ depending on the experimental group. The second set of experiments (groups 5-7) was designed to investigate the delayed (subacute) neurovascular changes of birth asphyxia and 24 hours of reventilation. In groups 5-7 the asphyxia was followed by 4 hours of reventilation with $\mathrm{RA}$ or $\mathrm{H}_{2}-\mathrm{RA}$ according to the experimental group, then it was switched to RA in all groups and continued for additional 18 hours.

The experimental groups were the following (Figure 1):

1) acute time control group ventilated with RA (group $1 ; n=9$ );

2) acute time control group ventilated with $\mathrm{H}_{2}-\mathrm{RA}$ (group $2 ; \mathrm{n}=7$ )

3) acute model of birth asphyxia with RA ventilation (group 3; n=8),

4) acute model of birth asphyxia with $\mathrm{H}_{2}-\mathrm{RA}$ ventilation (group 4; $\mathrm{n}=7$ ),

5) delayed time control animals ventilated with RA (group 5, n=9),

6) delayed model of birth asphyxia with RA ventilation (group 6, n=9), and

7) delayed model of birth asphyxia with $\mathrm{H}_{2}-\mathrm{RA}$ ventilation (group 7, $\mathrm{n}=9$ ). 


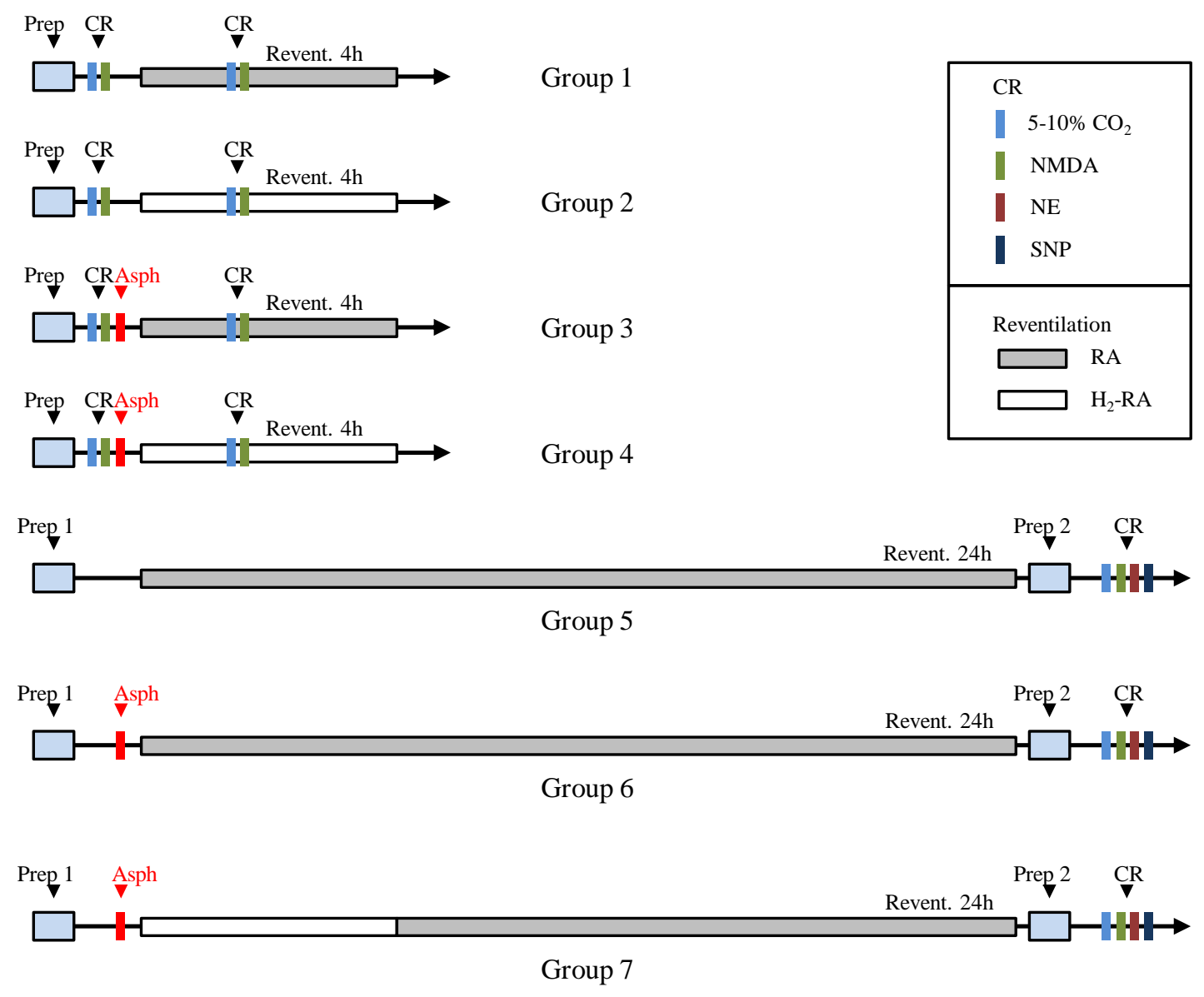

Figure 1. Experimental groups and design.

\section{Animal preparation and birth asphyxia}

\section{Acute model of HIE}

The animals were anesthetized with Na-thiopental $(30-40 \mathrm{mg} / \mathrm{kg}$ injected ip.) followed with an iv. injection of $\alpha$-chloralose (45 mg/kg). Supplemental doses of $\alpha$-chloralose were given to maintain a stable level of anesthesia determined by continuous monitoring of arterial blood pressure and responsiveness to tactile stimuli. The piglets were intubated via tracheotomy and mechanically ventilated with RA. The ventilation rate $(25-35 / \mathrm{min})$ and the peak inspiratory pressure $\left(100-125 \mathrm{mmH}_{2} \mathrm{O}\right)$ were adjusted to maintain the arterial blood gas values and $\mathrm{pH}$ in the physiological range. The right femoral artery and vein were catetherized to monitor arterial blood pressure, blood gases and $\mathrm{pH}$, and to administer drugs and fluids, respectively. Body temperature was maintained within a physiological range $\left(38-39^{\circ} \mathrm{C}\right)$ by an electric heating pad. 
After obtaining baseline CR values, asphyxia was induced (group 3 and 4) by suspending the artificial ventilation and clamping the endotracheal tube for $10 \mathrm{~min}$ (Figure 1). Reventilation started with the gas mixtures according to the protocol of the respective experimental groups. In the time control groups, ventilation was switched to the respective gas mixtures after a RA ventilation time control period $(10 \mathrm{~min})$. Following 1 hour ventilation, CR to hypercapnia and NMDA were repeatedly determined in all experimental groups, continued by ventilation for additional 3 hours. At the end of the 4-hours survival period, the anesthetized piglets were euthanized with $\mathrm{KCl}(2 \mathrm{M}, 10 \mathrm{~mL}$ iv.).

\section{Delayed model of HIE}

Anesthesia was induced with ip. injection of Na-thiopental $(45 \mathrm{mg} / \mathrm{kg})$ followed by intubation through tracheotomy and artificial ventilation with RA, using a pressure-controlled ventilator. The ventilation rate $(25-35 / \mathrm{min})$ and the peak inspiratory pressure (100-125 $\mathrm{mmH}_{2} \mathrm{O}$ ) were set to keep blood gases and oxygen saturation in the physiological range. The right femoral and jugular veins were catheterized to monitor $\mathrm{pH}, \mathrm{pCO} 2$, glucose, and to inject drugs and fluids, respectively. Anesthesia/analgesia was continued with iv. injection of loading dose of morphine $(100 \mu \mathrm{g} / \mathrm{kg})$, and midazolam $(250 \mu \mathrm{g} / \mathrm{kg})$, and was then maintained with intravenous infusion of morphine $(10 \mu \mathrm{g} / \mathrm{kg} / \mathrm{h})$, and midazolam $(250 \mu \mathrm{g} / \mathrm{kg} / \mathrm{h})$ along with fluids ( $5 \%$ glucose, $0.45 \% \mathrm{NaCl}, 2-5 \mathrm{ml} / \mathrm{kg} / \mathrm{h}$ ), with additional boluses if necessary. Every 12 hours intravenous antibiotics were given (penicillin $50 \mathrm{mg} / \mathrm{kg}$; gentamycin 2,5 mg $/ \mathrm{kg}$ ).

After the initial preparation, the animals were placed in a prone position into an ICU newborn resuscitation crib (SPC 78-1, Narco Air-Shields Inc., Hatboro, Pennsylvania, USA). Core body temperature was maintained within a physiological range $\left(38,5 \pm 0,5^{\circ} \mathrm{C}\right)$ with a servo-controlled overhead radiant heater. Additional heating was provided with an electric heating pad if necessary. Oxygen saturation, heart rate, ECG, arterial blood pressure, and body temperature were non-invasively monitored with a Hewlett Packard M1094 monitor (Palo Alto, California, USA); the data were on-line recorded using a PC (MecifView, Arlington, MA, USA). The aEEG was performed with two biparietal needle electrodes coupled to an EEG amplifier (Experimetria Ltd., Balatonfüred, Hungary), the raw EEG data were converted to aEEG recording and stored on a PC using a custom software designed according to the specifications described previously [102]. 


\begin{tabular}{|c|c|c|c|c|}
\hline Score & Description & Minimum & Maximum & \\
\hline 0 & Isoelectric & 0 & $<2 \mu \mathrm{V}$ & \\
\hline 1 & Low voltage & 0 & $<5 \mu \mathrm{V}$ & \\
\hline 2 & Burst suppression & $<5 \mu \mathrm{V}$ & $<10 \mu \mathrm{V}$ & \\
\hline 3 & Discontinuous 1 & $<5 \mu \mathrm{V}$ & $10-25 \mu \mathrm{V}$ & \\
\hline 4 & Discontinuous 2 & $<5 \mu \mathrm{V}$ & $<25 \mu \mathrm{V}$ & \\
\hline 5 & Continuous & $>5 \mu \mathrm{V}$ & $<25 \mu \mathrm{V}$ & \\
\hline
\end{tabular}

Table 1. aEEG evaluation scoring system.

In group 6 and 7, asphyxia was induced by suspending the ventilation for 8 minutes and continued with reventilation with the gas mixture according to the experimental group (Figure 1). Four hours following asphyxia the ventilation was continued with RA in every group. In the entire reventilation period, $\mathrm{FiO}_{2}$ was increased in some animals from $21 \%$ up to $25 \%$ to maintain satisfactory oxygenation. Vital parameters and aEEG were continuously monitored, and recorded for $10 \mathrm{~min}$ before the asphyxiation, during the asphyxia, for the first 10 minutes of reventilation and then 10-10 min from the 1 st to the $22^{\text {nd }}$ hours of reventilation each hour. The aEEG background pattern was evaluated with a scoring system (Table 1) based on [14]. Venous pH, blood gases, and blood glucose level were checked every 4 hours.

CR was determined sequentially to graded hypercapnia, NMDA (10 and 100 $\mu \mathrm{M})$, NA (10 and $100 \mu \mathrm{M})$, and SNP (1 and $10 \mu \mathrm{M}) 24$ hours after the asphyxia. After examination of CR the common carotid arteries were bilaterally cannulated in the deeply anesthetized animals and the brain was perfused with cold $\left(4^{\circ} \mathrm{C}\right)$ saline.

\section{Closed cranial window/intravital videomicroscopy and determination of CR}

To determine CR the anesthetized animals were equipped with a closed cranial window [103]. The head of the piglet was fixed in a stereotaxic frame. The scalp was incised and removed together with the connective tissue over the calvaria. A circular craniotomy was made in the left parietal bone. The dura was cut and reflected over the skull. A stainless steel cranial window with three injectable ports was placed into the craniotomy, sealed with bone wax and cemented with dental acrylic. The window was filled with artificial CSF (aCSF) warmed to $37^{\circ} \mathrm{C}$. The pial vessels $(\sim 100 \mu \mathrm{m}$ in diameter) were visualized with by using an operating microscope (Wild, Switzerland) equipped with a CCD camera (A.Krüss, Germany) connected to a video monitor. Vascular diameters were measured using video microscaler. 
After the visualized arteriole stabilized its baseline diameter, the window was flushed with aCSF. Vasodilator stimuli were: 1) graded hypercapnia (ventilation with gas mixture of 5 or $10 \% \mathrm{CO}_{2}, 21 \% \mathrm{O}_{2}$, balance $\left.\mathrm{N}_{2}\right)$, 2) local application of NMDA $\left.(10-100 \mu \mathrm{M}), 3\right)$ NA (10$100 \mu \mathrm{M})$, and 4) SNP $(1-10 \mu \mathrm{M})$. All drugs were dissolved in aCSF. The effects of hypercapnia and NMDA were tested for 5 minutes, of NA and SNP for 3 minutes. During each stimulus arteriolar diameters were observed continuously. After each stimulus the cranial window was repeatedly flushed with aCSF and the vessel diameter was allowed to return to baseline level.

\section{Drugs}

Sources: Na-thiopental (Sandoz, Kundl, Austria); morphine hydrochloride, penicillin (Teva, Petah Tikva, Israel); midazolam (Torrex Pharma, Vienna, Austria); gentamycin, NA (NA; Sanofi, Paris, France); $\alpha$-chloralose, N-methyl-D-aspartate (NMDA), sodium nitroprusside (SNP; Sigma Aldrich, St. Louis, MO, USA). All gas mixtures used for ventilation were obtained from the Messer Group Gmbh, Bad Soden, Germany.

\section{Neuropathology}

Additional group of piglets (NAIVE, $n=3$ ) were euthanized with Na-thiopental (150 $\mathrm{mg} / \mathrm{kg}$ i.p.) to provide an absolute control for the neuropathology studies. After euthanasia in all experimental groups, the brains were rapidly and carefully removed and immersion fixed in 4\% paraformaldehyde within 5-6 min. Tissue blocks from the frontal, parietal, temporal, and occipital cortices, the hippocampus, the cerebellum, the basal ganglia, the pons, and the medulla oblongata were embedded in paraffin, and sections were double stained with hematoxylin and eosin (H/E). Neuronal damage was evaluated on $\mathrm{H} / \mathrm{E}$ stained sections via determining the percentage of damaged, shrunken hyperchromatic (red) neurons with pyknotic nuclei compared with the total number of neurons by an examiner blinded to the experimental groups.

\section{COX-2 immunohistochemistry}

For COX-2 immunohistochemistry, brain samples from the frontal, parietal, temporal and occipital lobes of the cerebral cortex, the hippocampus, the caudate nucleus, the cerebellum, the pons, and the medulla oblongata of the animals of group 1, 2, 3 and 4 were dissected. The samples were dehydrated, paraffin embedded, and $4 \mu \mathrm{m}$ thin coronal sections were cut from the paraffin blocks. The sections were mounted on sylanized slides, were incubated at $56^{\circ} \mathrm{C}$ 
overnight, then dewaxed in xylene and rehydrated in descending alcohol gradient. Slides were incubated in $3 \% \mathrm{H}_{2} \mathrm{O}_{2}$ in methanol to block endogenous tissue peroxidase activity. Antigen retrieval was performed by boiling the slides for 3 min using citrate buffer $(\mathrm{pH}=6.0)$ solution. After cooling at room temperature, slides were incubated with a 1:200 dilution rabbit monoclonal primary antibody against COX-2 (clone SP21, Labvision, Fremont, California, USA) for 30min. The secondary anti-rabbit antibody was conjugated with high affinity horseradish peroxidase-polymer system (EnVision; Dako, Glostrup, Denmark). For visualization, 3,3'-diaminobenzidine (DAB) tetrahydrochloride solution was used. Slides were counterstained with hematoxylin then dehydrated in increasing concentrations of alcohol, cleared in xylene and coverslipped.

COX-2 immunoreactive neurons were manually counted by two independent observers blinded to the experimental group. In each examined brain region, the percentage of stained neurons was determined by dividing the number of immunopositive neurons by the total number of neurons observed in 5 randomly selected fields of view at $20 \times$ magnification using light microscopy. In addition, reflecting staining intensity the immunoreactive neurons were ranked: $1+, 2+$, or $3+$ scores were given corresponding with weak, perinuclear staining (1+), moderate cytoplasmic staining (2+) and strong cytoplasmic and dendritic staining (3+) respectively.

\section{MAP-2 immunohistochemistry}

For MAP-2 immunohistochemistry brain samples from group 5, 6 and 7 were used. Paraffin embedded sections $(4 \mu \mathrm{m})$ were mounted on sylanized slides, incubated at $56^{\circ} \mathrm{C}$ overnight, then dewaxed in xylene and rehydrated in descending alcohol gradient. The slides were incubated with a 1:200 dilution rabbit monoclonal anti-MAP-2 (ExBio, Czech Republic) for $30 \mathrm{~min}$ using an automatic slide stainer. The secondary anti-rabbit antibody was conjugated with high affinity horseradish peroxidase-polymer system (EnVision ${ }^{\circledR}$; Dako, Glostrup, Denmark). For visualization, DAB tetrahydrochloride solution was used. Slides were counterstained with hematoxylin then dehydrated in increasing concentrations of alcohol, cleared in xylene and coverslipped.

Evaluation of immunohistochemistry slides were performed according previously described methods [104]; briefly, images of whole labelled sections were scanned with automatic digital slide scanner (Panoramic MIDI, 3DHistech, Budapest, Hungary) and imported into Image Pro Plus 6.0 (Media Cybernetics, Bethesda, USA). Images were then 
converted to greyscale and thresholded at the same level in each image to produce images consisting only of black (labelled) or white (unlabelled) pixels. The percentage of the labelled (black) area was determined and designated as the MAP-2 score of the respective area.

\section{Laser speckle contrast analysis (LASCA) technique}

An additional group of piglets (group 8; $n=20$ ) were instrumented for Laser-speckle imaging. The methodology of anesthesia and implantation of the closed cranial was the same as described for the acute asphyxia model. However, the cranial window was illuminated in this case by the polarized light of a near infrared $(\lambda=808 \mathrm{~nm})$ diode laser. Speckle images were recorded by a monochrome camera (Pixelink PL-B771F, resolution: 1280×1024 pixels). Laser speckle images were stored on a personal computer and LASCA was performed offline according to a previously described method [105]. The relative changes in pial arteriolar diameters were also determined on the speckle contrast images.

The window was flushed gently with aCSF, and baseline perfusion images were obtained after a stabilisation period. Then the following vasoactive stimuli were applied: $\mathrm{H}_{2}$ supplemented room air $\left(2.1 \% \mathrm{H}_{2}, 21 \% \mathrm{O}_{2}\right.$, balance $\left.\mathrm{N}_{2}\right)$, graded hypercapnia (ventilation with gas mixture of 5 or $10 \% \mathrm{CO}_{2}, 21 \% \mathrm{O}_{2}$, balance $\left.\mathrm{N}_{2}\right)$, local application of NMDA $(100 \mu \mathrm{M})$, NA $(10-100 \mu \mathrm{M})$, and asphyxia-reventilation. The effects of hypercapnia, $\mathrm{H}_{2}-\mathrm{RA}$ and NMDA were tested for 5 minutes, NA for 3 minutes. During each stimulus speckle image series were taken continuously with 1 frame/s frequency.

\section{Statistical analysis}

Parametric data are expressed as mean \pm SEM. Data were analyzed with a statistical software (SigmaPlot 11, Systat Software Inc., San Jose, CA, USA). CR and physiological parameters were analyzed with two-way repeated measures ANOVA, the morphometric data and LASCA with one-way ANOVA. For pairwise comparisons the Student-Newman-Keuls post hoc test was used. In case histopathology data were not normally distributed were analyzed with Kruskal-Wallis ANOVA on Ranks followed by the Dunn's post hoc test for multiple comparisons. The aEEG scores of Group 6 and 7 were compared with the MannWhitney U-test. $\mathrm{P}$ values $<0.05$ were considered statistically significant. 


\section{Results}

The baseline values of all monitored vital parameters, such as mean arterial blood pressure, heart rate, $\mathrm{pH}$, blood gases, and body core temperature were in the physiologic range and did not differ significantly between the experimental groups.

\section{Acute effects of asphyxia on vital parameters and CR}

Asphyxia caused decrease in the MABP and CoBF that were similar in groups subjected to asphyxia (group 3 and 4). At the onset of reventilation, MABP stabilized at near baseline values by the end of first hour (Table 2). MABP values were thus similar when determining CR to hypercapnia and NMDA before and after A/R.

\begin{tabular}{|l|l|c|c|c|c|c|c|c|}
\hline \multirow{2nnyyyyyy}{n}{} & & & \multicolumn{7}{|c|}{ Reventilation } \\
\cline { 3 - 9 } Group 1 & MABP & Baseline & Asphyxia & $10 \mathrm{~min}$ & $1 \mathrm{~h}$ & $2 \mathrm{~h}$ & $3 \mathrm{~h}$ & $4 \mathrm{~h}$ \\
\cline { 3 - 9 } & CoBF & $100 \pm 0$ & N/A & N/A & $69 \pm 4$ & $65 \pm 3$ & $62 \pm 4$ & $63 \pm 4$ \\
\hline Group 2 & MABP & $70 \pm 7$ & N/A & N/A & $63 \pm 4$ & $57 \pm 7$ & $59 \pm 7$ & $63 \pm 8$ \\
\hline & CoBF & $100 \pm 0$ & N/A & N/A & $93 \pm 5$ & $80 \pm 8$ & $80 \pm 8$ & $85 \pm 11$ \\
\hline Group 3 & MABP & $77 \pm 4$ & $47 \pm 8$ & $70 \pm 3$ & $66 \pm 6$ & $60 \pm 4$ & $58 \pm 4$ & $65 \pm 4$ \\
\hline & CoBF & $100 \pm 0$ & $31 \pm 7$ & $83 \pm 4$ & $107 \pm 5$ & $101 \pm 9$ & $103 \pm 5$ & $105 \pm 7$ \\
\hline Group 4 & MABP & $74 \pm 5$ & $41 \pm 12$ & $70 \pm 3$ & $51 \pm 3$ & $63 \pm 5$ & $55 \pm 4$ & $57 \pm 4$ \\
\hline & CoBF & $100 \pm 0$ & $29 \pm 5$ & $96 \pm 5$ & $69 \pm 3^{*}$ & $81 \pm 6$ & $76 \pm 8^{*}$ & $79 \pm 10^{*}$ \\
\hline
\end{tabular}

Table 2. MABP (mmHg) and CoBF (PU) data

In the normoxic time control groups, the MABP remained in the normal range during the whole course of the experiment. CoBF seemed to slightly decrease by $15-20 \%$ in group 2 compared with group 1; however, this tendency did not reach statistical significance. In contrast, CoBF was moderately lower $(20-25 \%)$ in the group 4 compared with the group 3 (Table 2).

Asphyxia caused significant hypoxia, hypercapnia, acidosis in both groups subjected to birth asphyxia. Notably however, both at $30 \mathrm{~min}$ and at $1 \mathrm{~h}$ after asphyxia, $\mathrm{pCO}_{2}$ was significantly higher in group 3 compared with group 4, albeit $\mathrm{pH}$ and $\mathrm{pO}_{2}$ values were not significantly different (Table 3). 


\begin{tabular}{|c|c|c|c|c|c|c|c|c|c|c|}
\hline & & & $\begin{array}{r}\text { Hypercap } \\
\text { asp } \\
\end{array}$ & $\begin{array}{l}\text { nia before } \\
\text { yxia }\end{array}$ & & & Reventilatiol & & $\begin{array}{r}\text { Hyperca } \\
\text { aspl } \\
\end{array}$ & $\begin{array}{l}\text { nia after } \\
\text { xia }\end{array}$ \\
\hline & & Baseline & $5 \% \mathrm{CO}_{2}$ & $10 \% \mathrm{CO}_{2}$ & Asphyxia & $10 \mathrm{~min}$ & $30 \mathrm{~min}$ & $1 \mathrm{~h}$ & $5 \% \mathrm{CO}_{2}$ & $10 \% \mathrm{CO}_{2}$ \\
\hline Group 1 & $\mathrm{pH}$ & $7.53 \pm 0.02$ & $7.32 \pm 0.03$ & $7.15 \pm 0.02$ & N/A & $7.45 \pm 0.06$ & $7.46 \pm 0.05$ & $7.44 \pm 0.06$ & $7.30 \pm 0.03$ & $7.16 \pm 0.04$ \\
\hline & $\mathrm{PCO}_{2}(\mathrm{mmHg})$ & $26 \pm 2$ & $44 \pm 3$ & $65 \pm 10$ & N/A & $29 \pm 6$ & $32 \pm 7$ & $35 \pm 6$ & $51 \pm 5$ & $71 \pm 8$ \\
\hline & $\mathrm{PO}_{2}(\mathrm{mmHg})$ & $89 \pm 8$ & $89 \pm 7$ & $93 \pm 5$ & N/A & $92 \pm 9$ & $92 \pm 9$ & $84 \pm 9$ & $85 \pm 7$ & $93 \pm 5$ \\
\hline Group 2 & $\mathrm{pH}$ & $7.53 \pm 0.06$ & $7.30 \pm 0.02$ & $7.15 \pm 0.02$ & N/A & $7.46 \pm 0.04$ & $7.44 \pm 0.05$ & $7.42 \pm 0.05$ & $7.26 \pm 0.04$ & $7.09 \pm 0.03$ \\
\hline & $\mathrm{PCO}_{2}(\mathrm{mmHg})$ & $33 \pm 2$ & $51 \pm 5$ & $85 \pm 6$ & N/A & $34 \pm 3$ & $35 \pm 4$ & $37 \pm 6$ & $57 \pm 3$ & $85 \pm 5$ \\
\hline & $\mathrm{PO}_{2}(\mathrm{mmHg})$ & $78 \pm 3$ & $75 \pm 4$ & $66 \pm 7$ & N/A & $74 \pm 7$ & $75 \pm 9$ & $70 \pm 7$ & $77 \pm 6$ & $70 \pm 12$ \\
\hline Group 3 & $\mathrm{pH}$ & $7.3 \pm 0.10$ & $7.06 \pm 0.13$ & $7.09 \pm 0.04$ & $6.76 \pm 0.03$ & $7.06 \pm 0.07$ & $7.14 \pm 0.09$ & $7.20 \pm 0.09$ & $7.05 \pm 0.09$ & $7.04 \pm 0.04$ \\
\hline & $\mathrm{PCO}_{2}(\mathrm{mmHg})$ & $29 \pm 1$ & $51 \pm 6$ & $80 \pm 5$ & $133 \pm 10$ & $59 \pm 8$ & $43 \pm 5$ & $56 \pm 9$ & $71 \pm 12$ & $90 \pm 11$ \\
\hline & $\mathrm{PO}_{2}(\mathrm{mmHg})$ & $82 \pm 4$ & $86 \pm 4$ & $85 \pm 5$ & $11 \pm 1$ & $66 \pm 8$ & $61 \pm 5$ & $60 \pm 8$ & $70 \pm 9$ & $70 \pm 13$ \\
\hline Group 4 & $\mathrm{pH}$ & $7.28 \pm 0.09$ & $7.20 \pm 0.07$ & $7.05 \pm 0.05$ & $6.85 \pm 0.07$ & $7.12 \pm 0.07$ & $7.21 \pm 0.08$ & $7.24 \pm 0.09$ & $7.10 \pm 0.08$ & $7.01 \pm 0.06$ \\
\hline & $\mathrm{PCO}_{2}(\mathrm{mmHg})$ & $31 \pm 4$ & $48 \pm 5$ & $77 \pm 5$ & $123 \pm 12$ & $44 \pm 5$ & $32 \pm 4 *$ & $31 \pm 3^{*}$ & $54 \pm 5$ & $82 \pm 3$ \\
\hline & $\mathrm{PO}_{2}(\mathrm{mmHg})$ & $71 \pm 4$ & $81 \pm 4$ & $86 \pm 3$ & $5 \pm 0.4$ & $69 \pm 6$ & $66 \pm 4$ & $68 \pm 4$ & $78 \pm 5$ & $77 \pm 3$ \\
\hline
\end{tabular}

Table 3. Blood chemistry data in the acute period following asphyxia

Ventilation with gas mixtures containing $5 \%$ or $10 \% \mathrm{CO}_{2}$ to determine $\mathrm{CR}$ to graded hypercapnia resulted in graded increase in arterial $\mathrm{pCO}_{2}$ with simultaneous drops in $\mathrm{pH}$ in all groups before and after asphyxic event (Table 3).

Graded hypercapnia elicited significant, dose-dependent, pial arteriolar vasodilation in all experimental groups (Figure 2A). Baseline pial arteriolar diameters were not significantly different between repeated hypercapnia stimulations (first versus second stimulation: $85 \pm 4 \mu \mathrm{m}$ vs. $91 \pm 3 \mu \mathrm{m}$ for group 1 , and $86 \pm 6 \mu \mathrm{m}$ vs. $82 \pm 7 \mu \mathrm{m}$ for group $2,88 \pm 4 \mu \mathrm{m}$ vs. $94 \pm 8 \mu \mathrm{m}$ for group $3,87 \pm 4 \mu \mathrm{m}$ vs. $92 \pm 7 \mu \mathrm{m}$ for group 4$)$. A/R significantly reduced CR to hypercapnia in group 3 (Figure 2A) but not in the other experimental groups (Figure 2A). Thus, ventilation with $\mathrm{H}_{2}-$ RA under normoxic conditions in group 2 did not affect CR to hypercapnia. Furthermore, ventilation with $\mathrm{H}_{2}$-RA after asphyxia prevented the reduction of CR to hypercapnia in the group 4 (Figure $2 \mathrm{~A}$ ). 


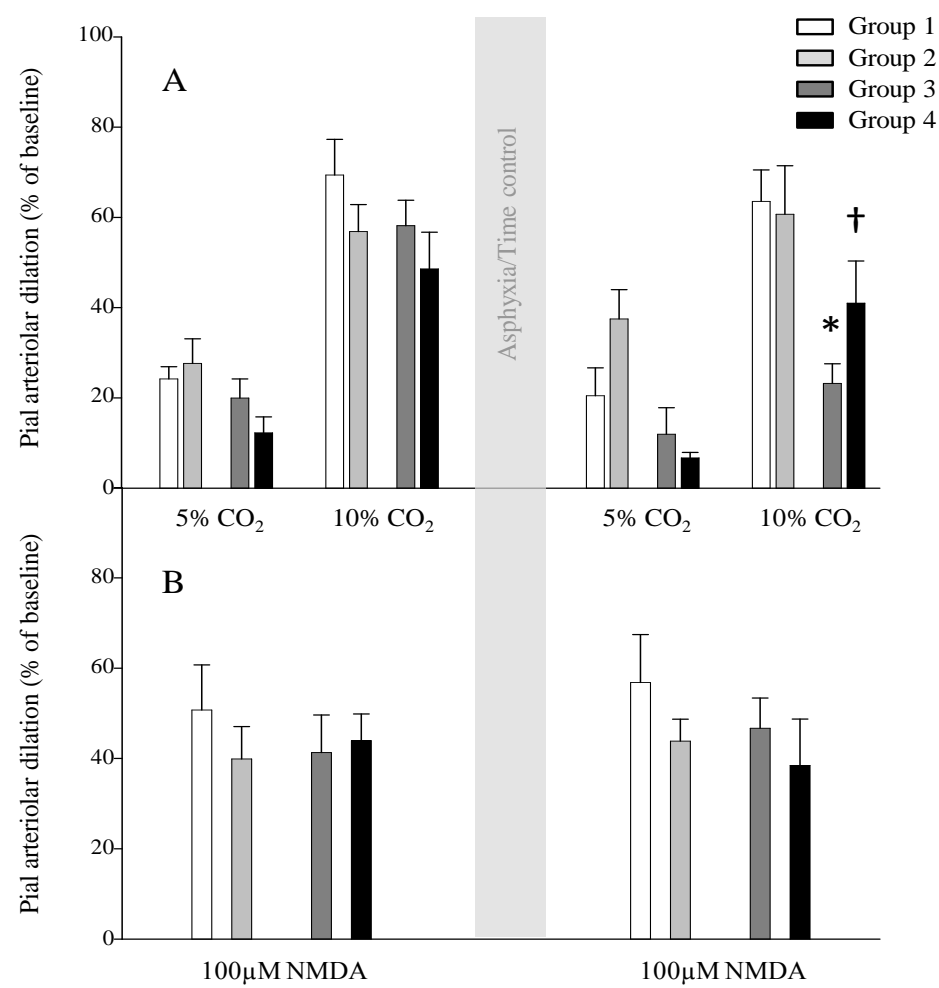

Figure 2. Ventilation with $\mathrm{H}_{2-}$ supplemented room air preserves CR to hypercapnia 1 hour after asphyxia. Both stimuli (hypercapnia and topical application of NMDA) elicited similar, significant increases in pial arteriolar diameters in all experimental groups. In time control groups, responses were repeatable and similar between group 1 and 2. After asphyxia pial arteriolar dilation to $10 \% \mathrm{CO}_{2}$ was significantly reduced in group 3 , however in group 4 it was not significantly different from the respective baseline response before asphyxia. $\mathrm{p}<0,05 *$ versus corresponding response before asphyxia, $\dagger$ versus corresponding response after asphyxia in group 3 .

NMDA induced significant, repeatable pial arteriolar vasodilation before and after $\mathrm{A} / \mathrm{R}$ in all experimental groups (Figure 2B). Baseline pial arteriolar diameters did not differ significantly between repeated NMDA applications (first versus second application: $86 \pm 4 \mu \mathrm{m}$ vs. $82 \pm 4 \mu \mathrm{m}$ for group 1 , and $84 \pm 5 \mu \mathrm{m}$ vs. $80 \pm 6 \mu \mathrm{m}$ for group $2,87 \pm 4 \mu \mathrm{m}$ vs. $85 \pm 9 \mu \mathrm{m}$ for group $3,85 \pm 4 \mu \mathrm{m}$ vs. $91 \pm 6 \mu \mathrm{m}$ for group 4$)$.

\section{Neuropathology - acute neuronal changes}

The percentage of damaged neurons was negligible in any brain region of the untreated control animals (NAIVE animals): the median value was $0 \%$ in seven regions (temporal and occipital cortices, CA1, CA2, CA3 and granular region of the hypocampus and cerebellum), $2 \%$ in three regions (frontal cortex, caudate nucleus and medulla), and $3 \%$ in two regions (parietal cortex and pons).

In the time control animals (group 1 and 2), there was also only a $1-4 \%$ neuronal damage depending on the brain region studied, indicating that $\mathrm{H}_{2}-\mathrm{RA}$ ventilation alone did not affect neuronal viability (Figs. 3 and $4 \mathrm{~A}-\mathrm{C}$ ). A/R significantly increased neuronal injury in all brain regions studied in the group 3. However, the increase in injured, red neurons was 
smaller in group 4, showing neuroprotective effect in virtually all examined brain regions (Figs. 3 and $4 \mathrm{~A}-\mathrm{C}$ ).

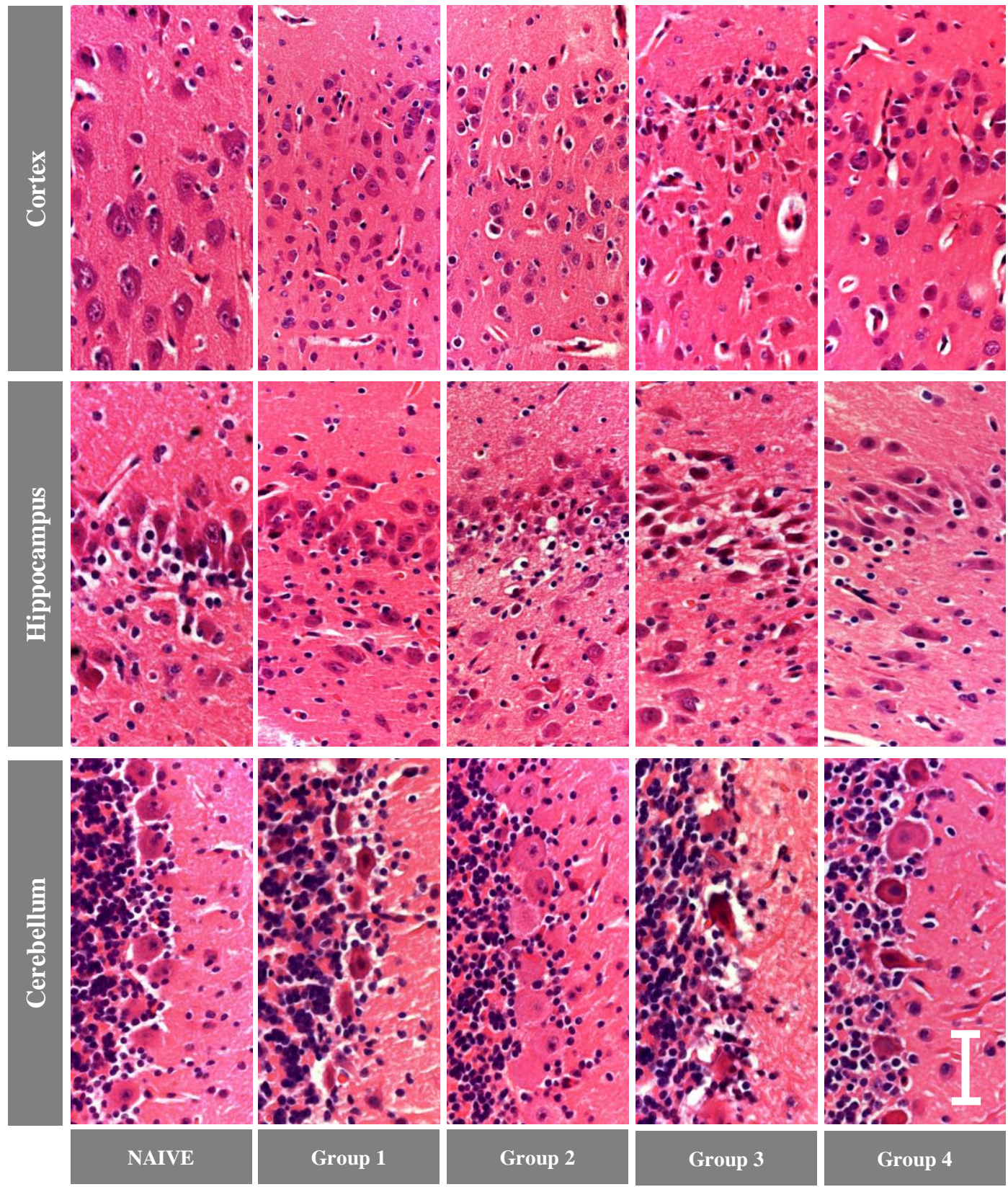

Figure 3. Representative photomicrographs from the parietal cortex, the stratum granulare of the hippocampus, and the cerebellar cortex showing neuroprotection by $\mathrm{H}_{2}-\mathrm{RA}$ ventilation in the early survival period ( $4 \mathrm{~h}$ reventilation). Shrunken, hyperchromatic (red) neurons with pyknotic nuclei are more common in samples obtained from animals of the group 3 as compared with group 4. Time control groups (group 1 and 2) show minimal neuronal damage, the samples are similar to those obtained from untreated (NAIVE) animals. Scale bar: $100 \mu \mathrm{m}$. 


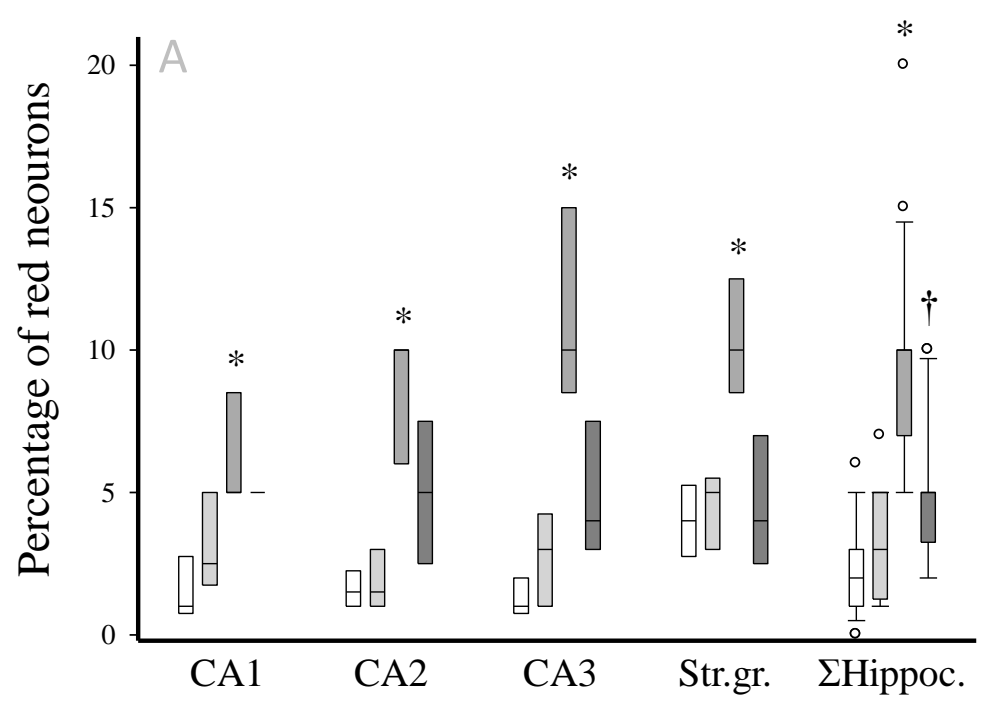

Figure 4. Neuronal injury was quantitatively determined by cell counting at $4 \mathrm{~h}$ survival after asphyxia and in corresponding time control animals. The examined brain regions were Panel A: CA1, CA2, CA3, and stratum granulosum of the hippocampus; Panel B: frontal, parietal, temporal and occipital cortices; and Panel C: basal ganglia, pons, medulla, and

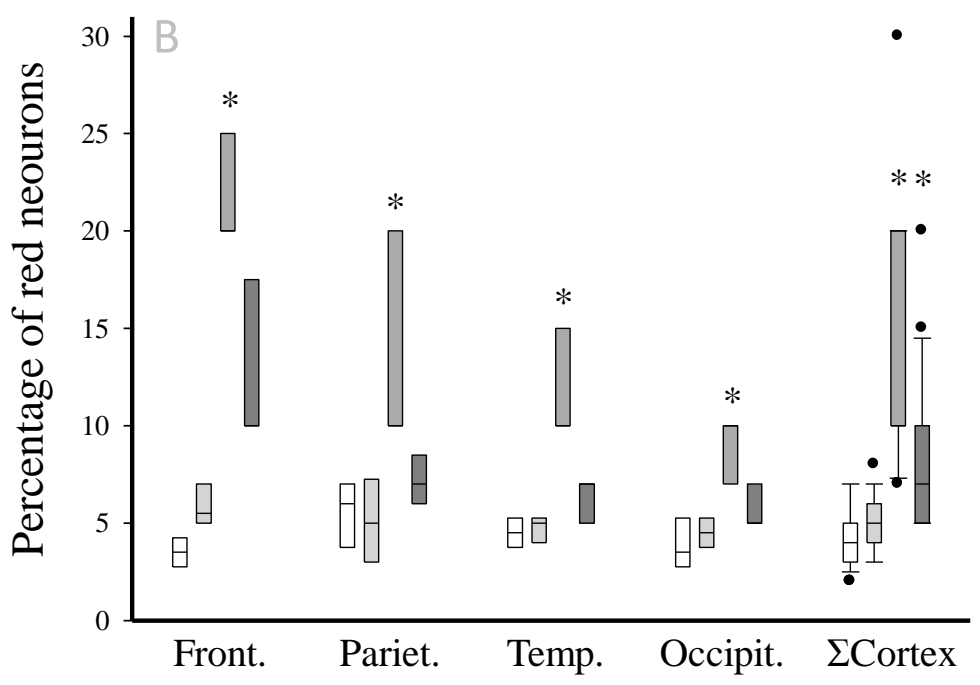
cerebellum. Pooled data from the hippocampal and cortical subregions are also shown on Panels A and B, respectively. The box plots show the median (horizontal line), the 25th75th percentile (box), the 10th-90th percentile (error bars), and any outlying data points (bullets). The experimental groups are represented by white, light gray, gray and dark gray boxes for groups 1, 2, 3, and 4 , respectively. $\mathrm{A} / \mathrm{R}$ resulted in significant increases in neuronal injury in virtually all examined brain regions in group 3 but not in group 4 compared with the respective time controls. $\mathrm{P}<0.05$, * versus corresponding time control, $\dagger$ group 3 versus group 4 . 


\section{Regional COX-2 expression}

We determined the ratio of COX-2 immunopositive neurons in various brain regions in the 4 acute groups of piglets (group 1-4) undergoing the $A / R$ and/or the neuroprotective hydrogen ventilation treatment (Table 4).

\begin{tabular}{|c|c|c|c|c|c|c|c|c|c|}
\hline & \multicolumn{4}{|c|}{ Cortex } & \multicolumn{4}{|c|}{ Hippocampus } \\
\hline & & Frontal & Parietal & Temporal & Occipital & CA1 & CA2 & CA3 & $\begin{array}{c}\text { Granular } \\
\text { layer }\end{array}$ \\
\hline \multirow[t]{4}{*}{ Group $1(n=8)$} & $1+$ & $28 \pm 6$ & $34 \pm 4$ & $17 \pm 3$ & $16 \pm 3$ & \multirow[b]{4}{*}{$14 \pm 3$} & \multirow[b]{4}{*}{$4 \pm 1$} & \multirow[b]{4}{*}{$3 \pm 1$} & \multirow[b]{4}{*}{$3 \pm 1$} \\
\hline & $2+$ & $16 \pm 3$ & $21 \pm 3$ & $8 \pm 1$ & $7 \pm 1$ & & & & \\
\hline & $3+$ & $5 \pm 1$ & $7 \pm 1$ & $7 \pm 3$ & $4 \pm 1$ & & & & \\
\hline & $\Sigma$ & $48 \pm 7$ & $62 \pm 6$ & $31 \pm 4$ & $27 \pm 4$ & & & & \\
\hline \multirow[t]{4}{*}{ Group $2(\mathrm{n}=7)$} & $1+$ & $34 \pm 4$ & $34 \pm 5$ & $21 \pm 2$ & $15 \pm 3$ & \multirow[b]{4}{*}{$10 \pm 3$} & \multirow[b]{4}{*}{$3 \pm 1$} & \multirow[b]{4}{*}{$2 \pm 1$} & \multirow[b]{4}{*}{$2 \pm 1$} \\
\hline & $2+$ & $16 \pm 3$ & $19 \pm 4$ & $13 \pm 2$ & $9 \pm 2$ & & & & \\
\hline & $3+$ & $10 \pm 4$ & $9 \pm 2$ & $7 \pm 2$ & $5 \pm 1$ & & & & \\
\hline & $\Sigma$ & $60 \pm 5$ & $63 \pm 8$ & $40 \pm 2$ & $29 \pm 4$ & & & & \\
\hline \multirow[t]{4}{*}{ Group $3(n=6)$} & $1+$ & $27 \pm 8$ & $28 \pm 4$ & $26 \pm 6$ & $17 \pm 4$ & \multirow[b]{4}{*}{$12 \pm 2$} & \multirow[b]{4}{*}{$3 \pm 0$} & \multirow[b]{4}{*}{$1 \pm 0$} & \multirow[b]{4}{*}{$2 \pm 1$} \\
\hline & $2+$ & $25 \pm 7$ & $26 \pm 4$ & $14 \pm 1$ & $12 \pm 3$ & & & & \\
\hline & $3+$ & $13 \pm 5$ & $12 \pm 3$ & $8 \pm 2$ & $7 \pm 2$ & & & & \\
\hline & $\Sigma$ & $65 \pm 12$ & $66 \pm 6$ & $48 \pm 9$ & $36 \pm 8$ & & & & \\
\hline \multirow[t]{4}{*}{ Group $4(n=5)$} & $1+$ & $33 \pm 5$ & $32 \pm 8$ & $25 \pm 3$ & $18 \pm 4$ & \multirow[b]{4}{*}{$24 \pm 7$} & \multirow[b]{4}{*}{$8 \pm 5$} & \multirow[b]{4}{*}{$2 \pm 1$} & \multirow[b]{4}{*}{$5 \pm 3$} \\
\hline & $2+$ & $23 \pm 2$ & $37 \pm 4$ & $16 \pm 3$ & $12 \pm 3$ & & & & \\
\hline & $3+$ & $10 \pm 2$ & $13 \pm 3$ & $9 \pm 4$ & $6 \pm 1$ & & & & \\
\hline & $\Sigma$ & $66 \pm 5$ & $81 \pm 5$ & $49 \pm 4$ & $36 \pm 7$ & & & & \\
\hline
\end{tabular}

Table 4. The percentage of COX-2 immunopositive neurons in the piglet cerebral cortex and hippocampus

COX-2 immunopositivity was observed in neurons and in microvessels. We observed COX-2 immunopositive neurons cortical samples from all cerebral lobes, in all cortical layers (Figure 5A-D). Marked neuronal COX-2 positivity was found in two distinct layers of the cerebral cortex: in the oval-shaped cells in cortical layer III and pyramidal cells in layer V. There was no statistically significant difference among the 4 experimental groups (group 1, 2, 3 and 4) either in the ratio of immunopositive neurons or their staining intensity (Table 4). In contrast, we observed striking regional differences in the ratio of COX-2 immunopositive neurons among the four cerebral lobes. To assess this interesting observation, data from normoxic and asphyxiated animals were pooled to better detect the regional differences. COX-2 immunoreactive neurons were almost twice as numerous in the frontal and the parietal cortices, than in the temporal and the occipital lobes (Figures 5A-D and 6A). Interestingly, this regional difference was not reflected in the staining intensity of the immunopositive 
neurons; instead, the proportions of $1+, 2+, 3+$ neurons were remarkably similar in all 4 regions: $\sim 50 \%, 35 \%, 15 \%$, respectively (Figure 6C).

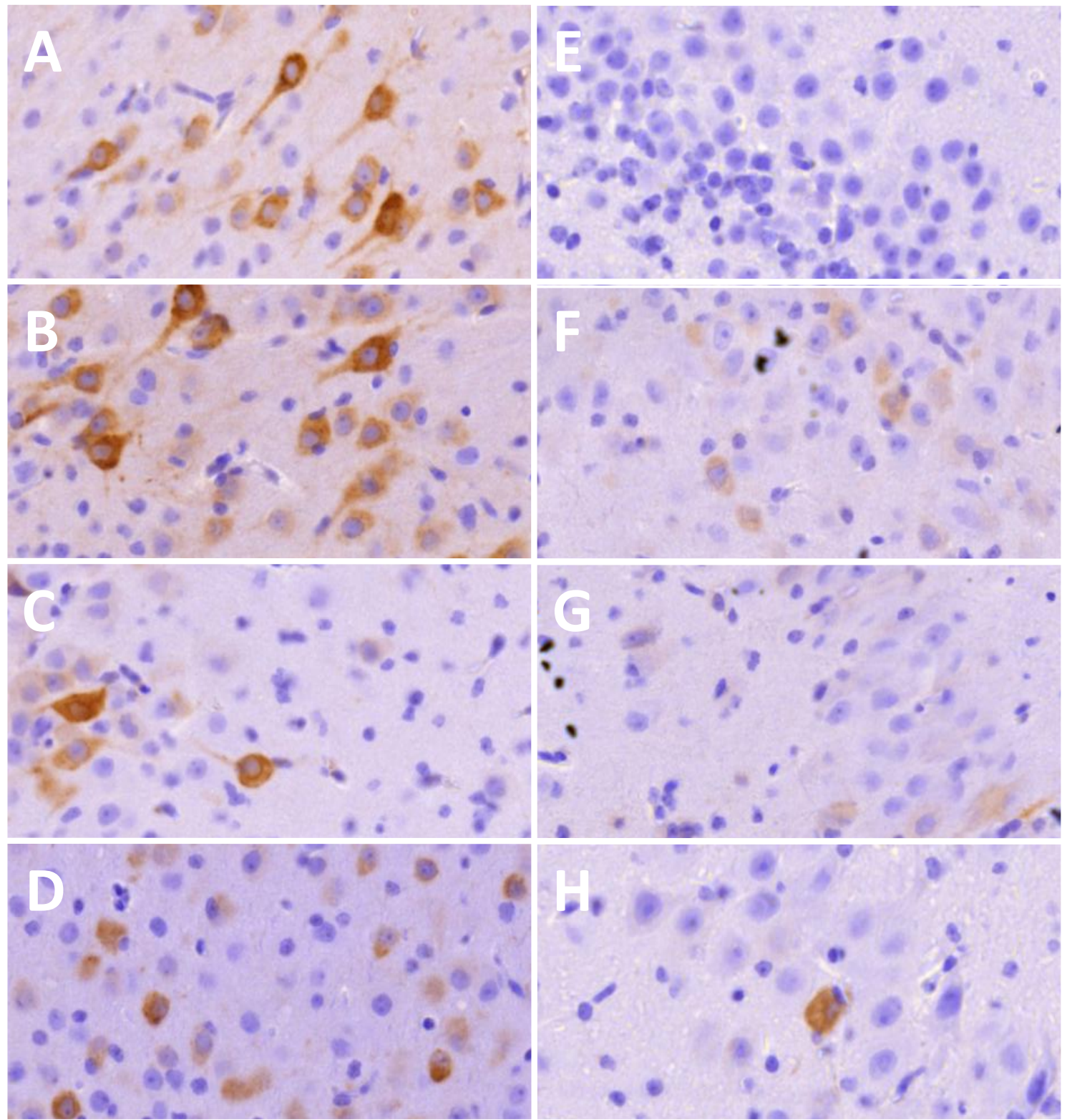

Figure 5. Representative photomicrographs showing COX-2 immunostaining in different regions of the of newborn pig brain. In the frontal (A) and the parietal cortex (B) strong cytoplasmic and dendritic expression can be observed in large percentage of the neurons, unlike in the temporal (C) and occipital cortex (D). All subregions of the hippocampus, such as the granular layer $(\mathrm{E})$, the CA1 $(\mathrm{F})$, the CA2 $(\mathrm{G})$, and the CA3 $(\mathrm{H})$ show generally weak neuronal staining. Scale bar represents $100 \mu \mathrm{m}$.

In the hippocampus, COX-2 immunostaining was considerably less pronounced than in the cortex with only few immunopositive neurons (Figure 5E-H). There was also no 
significant difference among the 4 experimental groups (Table 4). The highest expression was found in the pyramidal cells of the CA1 field, while there was minimal immunopositivity in the $\mathrm{CA} 2, \mathrm{CA} 3$ regions and the granular layer of the hippocampus (Figure 6B). The staining intensity could not be reliably evaluated due to the scarcity of immunopositive neurons. A

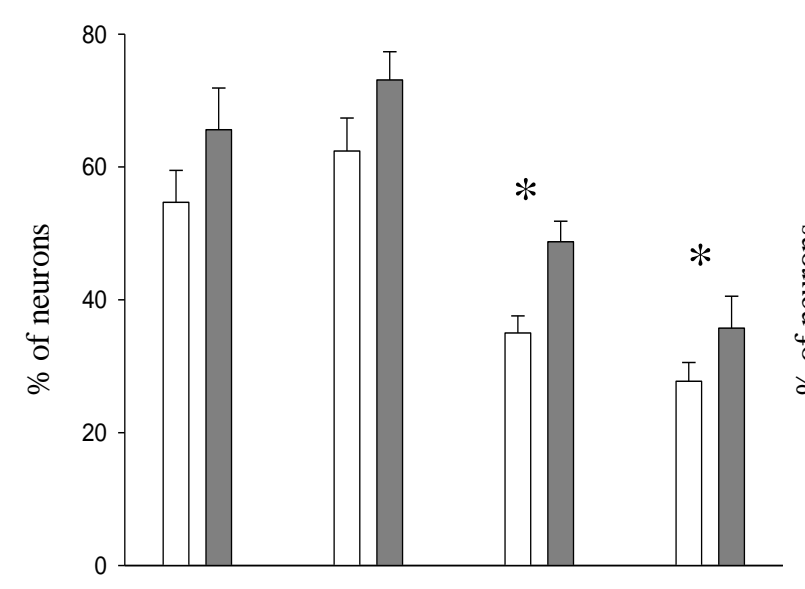

C

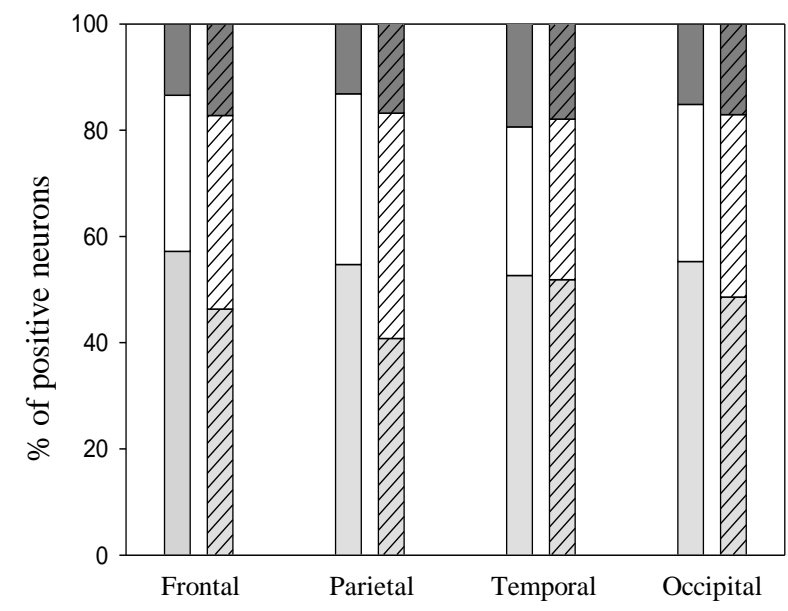

$\mathrm{B}$

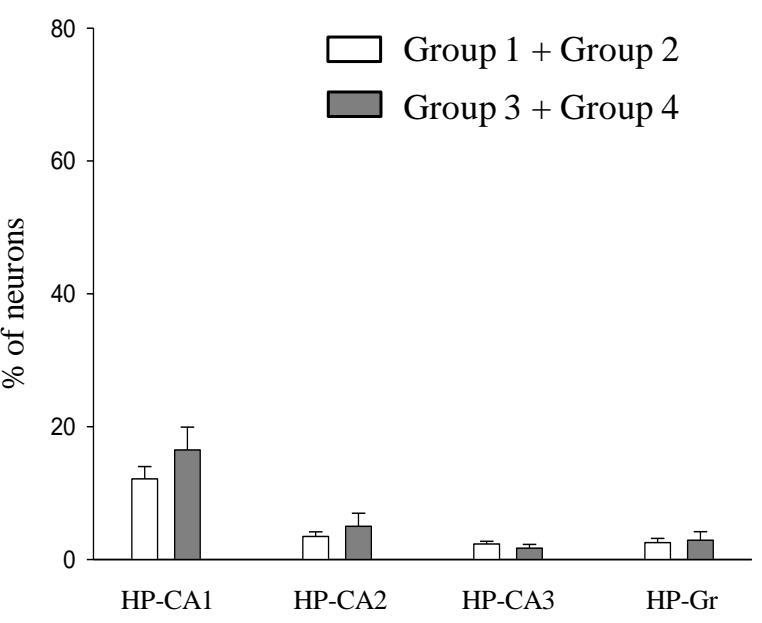

Figure 6. Regional neuronal COX-2 expression and staining intensity in the piglet cortex. The examined brain regions were: Panel A: Frontal, Parietal, Temporal and Occipital cortices, Panel B: CA1 (HP-CA1), CA2 (HP-CA2), CA3 (HP-CA3), Stratum granulosum (HP-Gr) hippocampal subregions. On Panels $\mathrm{A}$ and $\mathrm{B}$ the percentage of COX-2 positive neurons compared to the total number of neurons were plotted on the bar graphs (mean $\pm \mathrm{SEM}$ ), while on Panel $\mathrm{C}$ the staining intensity grades were plotted in percentage of total number of labelled neurons. In the neocortex, the temporal and occipital cortices show significantly lower basal COX-2 expression than the frontal and the parietal regions (Panel $\mathrm{A},{ }^{*} \mathrm{p}<0.05$, versus the frontal and the parietal cortices). However, the staining intensity grades of COX-2 immunopositivity showed a very similar pattern in all neocortical areas (Panel C). In the hippocampus, all subregions displayed low percentage of COX-2 immunopositive neurons (Panel B). 
In the assessed subcortical regions, there was no remarkable COX-2 immunostaining. The numbers of stained neurons were less than $1 \%$ showing patchy staining of neurons in the pons, medulla, cerebellum, and the caudate nucleus. In the cerebellum, COX-2 immunopositivity was observed in a small fraction of the Purkinje cells. Similar to the cortical regions, asphyxia or $\mathrm{H}_{2}-\mathrm{RA}$ ventilation did not cause significant alteration in the minimal COX-2 immunostaining.

\section{Delayed changes in vital parameters and CR following birth asphyxia}

In the time control group, the monitored physiological parameters (heart rate, blood pressure, blood gases and $\mathrm{pH}$, core body temperature and $\mathrm{O}_{2}$ saturation) were stable and within the physiological range (Figure 7). The aEEG showed continuous activity (score 5) throughout the whole observation period. In groups exposed to asphyxia, it caused isoelectric aEEG within 1-2 minutes (score 0), and severe hypoxia, hypercapnia, hypotension and bradycardia developed by the end of the asphyxic period. During reventilation these physiological parameters gradually recovered in 2-3 hours and then they did not differ from the time controls (Figure 7). The isoelectric aEEG recovered with large interindividual variability by the 22 hours observation period, although there was marked tendency of faster recovery in the $\mathrm{H}_{2}$-RA ventilated group that was statistically significant in the first 4 hours of reventilation (Figure 8). 

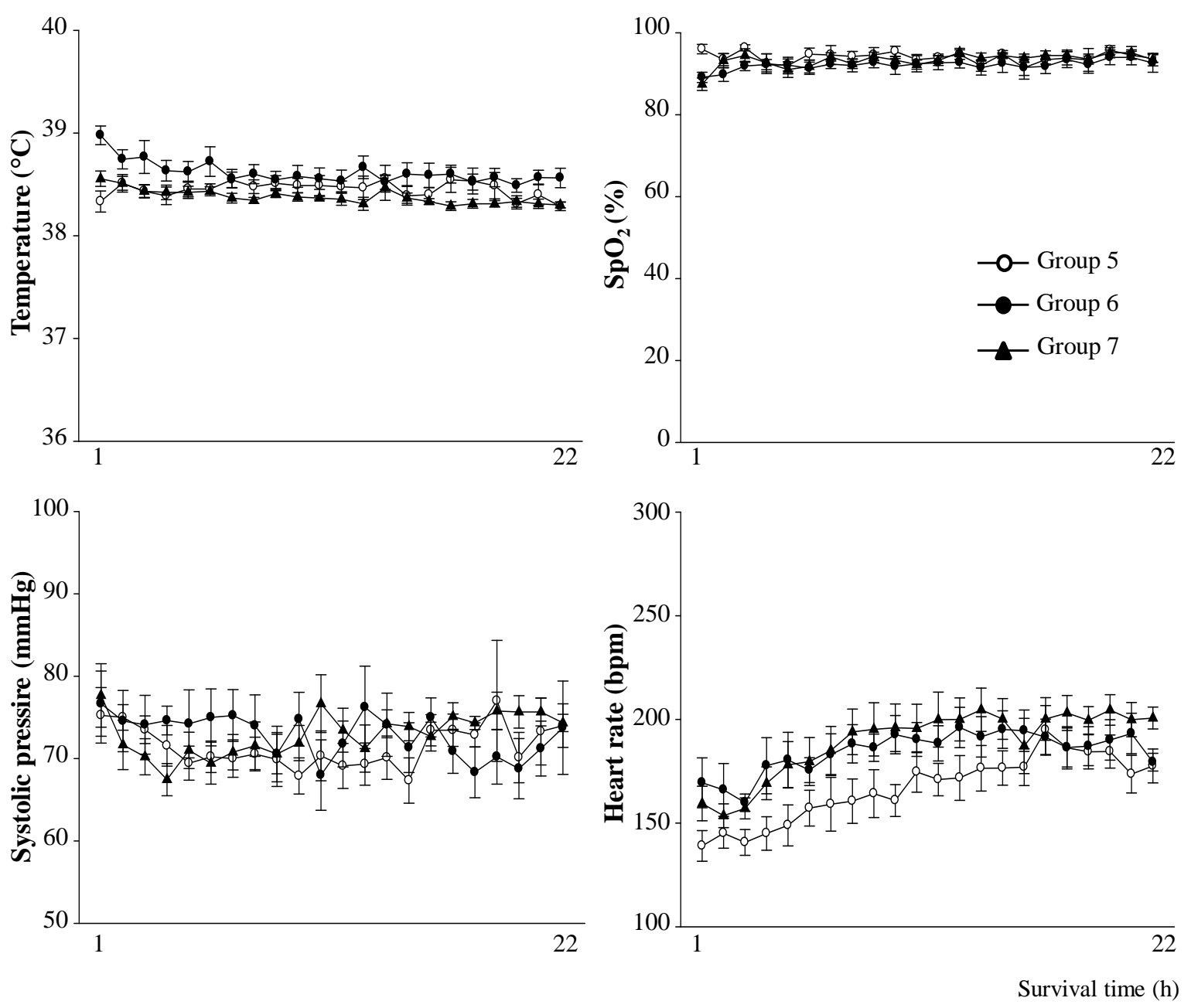

Figure 7. Rectal temperature and hemodynamic parameters in the experimental groups 5-7 over the course of 22 hours after asphyxia. Body temperature was tightly regulated and did not significantly differ among the experimental groups. The oxygen saturation was gradually restored within 3 hours after asphyxia and later did not differ significantly from the values obtained in time controls. Systolic blood pressure was also in the physiological range and was not different among groups. Asphyxia resulted in tachycardia during the early reventilation period that was later restored, however the animals exposed to asphyxia showed a tendency for elevated heart rate throughout the observation period. 


\begin{tabular}{|c|c|c|c|c|c|c|c|c|c|}
\hline & \multicolumn{3}{|c|}{ Group 5 (n=9) } & \multicolumn{3}{c|}{ Group 6 (n=9) } & \multicolumn{3}{c|}{ Group 7 (n=9) } \\
\cline { 2 - 11 } & $\mathrm{pH}$ & $\mathrm{pCO}_{2}$ & glucose & $\mathrm{pH}$ & $\mathrm{pCO}_{2}$ & glucose & $\mathrm{pH}$ & $\mathrm{pCO}_{2}$ & glucose \\
\hline & $7,4 \pm 0,2$ & $36 \pm 10$ & $3,5 \pm 1,6$ & $7,4 \pm 0,1$ & $39 \pm 6$ & $5,6 \pm 2,8$ & $7,4 \pm 0,1$ & $36 \pm 9$ & $5,9 \pm 5,0$ \\
\hline Baseline & & & & $6,9 \pm 0,1^{*}$ & $89 \pm 34^{*}$ & & $7,0 \pm 0,1^{*}$ & $94 \pm 14^{*}$ & \\
\hline Asphyxia & & & & $4,4 \pm 0,1$ & $45 \pm 10$ & $4,3 \pm 1,4$ & $7,4 \pm 0,1$ & $42 \pm 16$ & $3,7 \pm 1,5$ \\
\hline $4 \mathrm{~h}$ & $7,4 \pm 0,1$ & $43 \pm 10$ & $4,0 \pm 2,1$ & $7,4 \pm$ & 4,10 & $4,5 \pm 10$ & $4,5 \pm 3,2$ \\
\hline $8 \mathrm{~h}$ & $7,3 \pm 0,1$ & $47 \pm 18$ & $3,3 \pm 1,7$ & $7,3 \pm 0,1$ & $43 \pm 10$ & $4,5 \pm 2,8$ & $7,3 \pm 0,1$ & $48 \pm 10$ \\
\hline $12 \mathrm{~h}$ & $7,3 \pm 0,1$ & $49 \pm 18$ & $4,3 \pm 3,0$ & $7,3 \pm 0,1$ & $45 \pm 14$ & $4,0 \pm 1,5$ & $7,3 \pm 0,1$ & $45 \pm 14$ & $3,9 \pm 2,5$ \\
\hline $16 \mathrm{~h}$ & $7,3 \pm 0,2$ & $48 \pm 17$ & $3,2 \pm 1,3$ & $7,3 \pm 0,1$ & $49 \pm 16$ & $4,9 \pm 2,8$ & $7,4 \pm 0,1$ & $50 \pm 10$ & $3,1 \pm 1,0$ \\
\hline $20 \mathrm{~h}$ & $7,4 \pm 0,1$ & $38 \pm 12$ & $4,3 \pm 2,0$ & $7,3 \pm 0,1$ & $47 \pm 17$ & $2,8 \pm 0,4$ & $7,3 \pm 0,1$ & $53 \pm 19$ & $3,1 \pm 0,5$ \\
\hline
\end{tabular}

Table 5. Venous blood $\mathrm{pH}, \mathrm{pCO}_{2}(\mathrm{mmHg})$ and glucose levels $(\mathrm{mM})$ during the observation period. ${ }^{*} \mathrm{p}<0,05$ versus respective baselines.

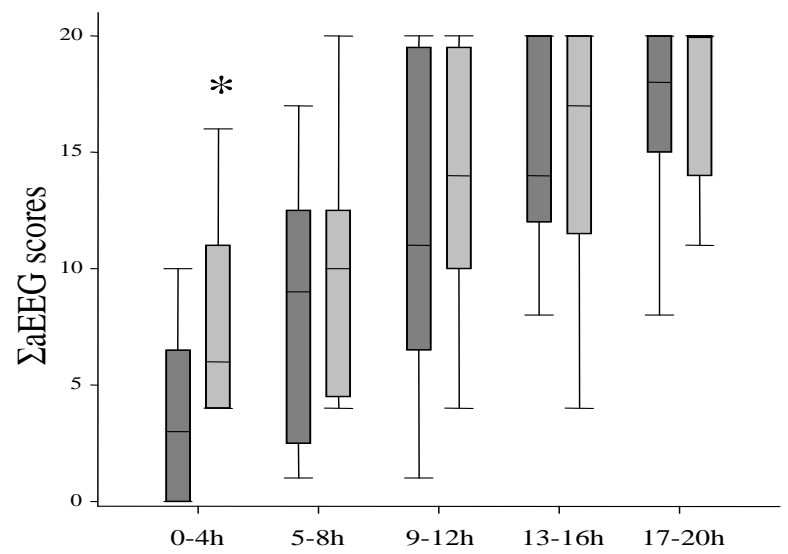

Figure 8. aEEG scores in groups 6 and 7 over the course of 20 hours after asphyxia. aEEG scores were determined each hour of survival were summated over 4-hour periods. The aEEG score in every animal of the time control group (group 5) was 5 throughout the observation period (not illustrated). Dark gray boxes are representing group 6, light gray boxes group 7. The presented box plots show the median value (thick line), the $25-75^{\text {th }}$ percentile (box), and the $10-90^{\text {th }}$ percentile (error bars). * $\mathrm{p}<0,05$ versus asphyxia.

Graded hypercapnia resulted in similar increase in arterial $\mathrm{pCO}_{2}$ together with decrease in $\mathrm{pH}$ in all experimental groups (Table 5). 5-10\% $\mathrm{CO}_{2}$ ventilation caused dosedependent pial arteriolar dilation in Group 5 (Figure 9A). In contrast, CR to graded hypercapnia was severely impaired 24 after asphyxia in group 6, but intrinsically unaffected in the animals ventilated with $\mathrm{H}_{2}-\mathrm{RA}$ (group 7; Figure 9A).

\begin{tabular}{|c|c|c|c|c|c|c|c|c|c|}
\hline & \multicolumn{3}{|c|}{ Baseline } & \multicolumn{3}{|c|}{$5 \% \mathrm{CO}_{2}$} & \multicolumn{3}{|c|}{$10 \% \mathrm{CO}_{2}$} \\
\hline & $\mathrm{pH}$ & $\mathrm{pCO}_{2}$ & $\mathrm{pO}_{2}$ & $\mathrm{pH}$ & $\mathrm{pCO}_{2}$ & $\mathrm{pO}_{2}$ & $\mathrm{pH}$ & $\mathrm{pCO}_{2}$ & $\mathrm{pO}_{2}$ \\
\hline Group 5 & $7.43 \pm 0.03$ & $35 \pm 4$ & $91 \pm 5$ & $7.32 \pm 0.02$ & $43 \pm 3$ & $96 \pm 4$ & $7.19 \pm 0.02$ & $60 \pm 3$ & $99 \pm 8$ \\
\hline Group 6 & $7.42 \pm 0.03$ & $36 \pm 4$ & $77 \pm 5$ & $7.30 \pm 0.01$ & $41 \pm 4$ & $85 \pm 9$ & $7.17 \pm 0.02$ & $64 \pm 3$ & $87 \pm 7$ \\
\hline Group 7 & $7.38 \pm 0.04$ & $40 \pm 4$ & $79 \pm 4$ & $7.30 \pm 0.03$ & $48 \pm 4$ & $83 \pm 5$ & $7.19 \pm 0.02$ & $69 \pm 2$ & $89 \pm 6$ \\
\hline
\end{tabular}

Table 5. Arterial blood $\mathrm{pH}, \mathrm{pCO}_{2}(\mathrm{mmHg})$, and $\mathrm{pO}_{2}(\mathrm{mmHg})$ values during graded hypercapnia

NMDA caused graded vasodilation in group 5, but it was abolished in group 6, and severely attenuated in group 7 , however CR to NMDA was significantly higher in $\mathrm{H}_{2}-\mathrm{RA}$ ventilated group (group 7) compared to RA group (group 6; Figure 9B). 
The arteriolar constriction to NA or dilation to SNP was not significantly affected by
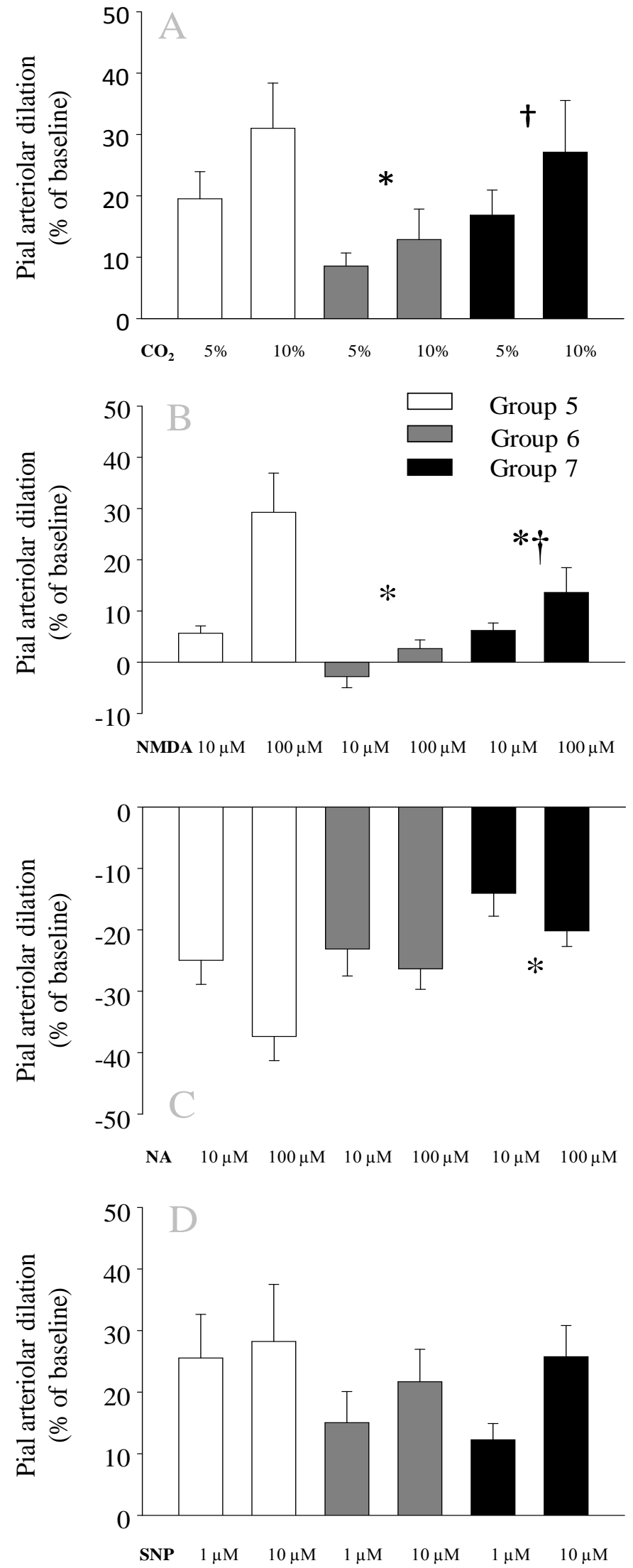

asphyxia, although it is remarkable that NA caused significantly smaller vasoconstriction in group 7 compared to time control animals (group 5; Figures 9C and D).

Figure 9. CR determined to various stimuli 24 hours after asphyxia. Baseline pial arteriolar diameters were not significantly different among the experimental groups. Panel A: Graded hypercapnia elicited concentrationdependent vasodilation that vas severely attenuated in the asphyxiated animals. Panel B: NMDA elicited dosedependent vasodilation that was abolished after asphyxia. NMDA-induced vasodilation was also significantly attenuated in the $\mathrm{H}_{2}$ ventilated group, however, the response was significantly larger compared to the RAventilated group. Panel C: NA elicited pial arteriolar constriction that was significantly altered by asphyxia. NA-induced vasoconstriction was significantly smaller in the $\mathrm{H}_{2}$-ventilated group. Panel D: SNP could dilate pial arterioles in all three experimental groups, although there was a tendency for smaller responses in the animals subjected to asphyxia. $\mathrm{p}<0,05 *$ versus group $5, \dagger$ versus group 6 . 


\section{Delayed neuronal injury at $24 \mathrm{~h}$ survival}

In group 5, there was only a mild perivascular edema with no gross histological alteration discernible in any brain regions studied. Accordingly, the neuronal injury was minimal in all regions (Figure 10). In group 6, asphyxia elicited only small, nevertheless statistically significant increases in the percentage of irreversibly damaged neurons in most neocortical areas, the CA1 region of the hippocampus, the cerebellum, and the medulla oblongata (Figures 10). $\mathrm{H}_{2}-\mathrm{RA}$ in group 7 resulted in a modest neuroprotective effect: neuronal damage was significantly smaller in the frontal cortex (vs. group 6), and there was no significant difference between group 5 and 7 in the CA1 region, the cerebellum, and the medulla oblongata (Figure 10).

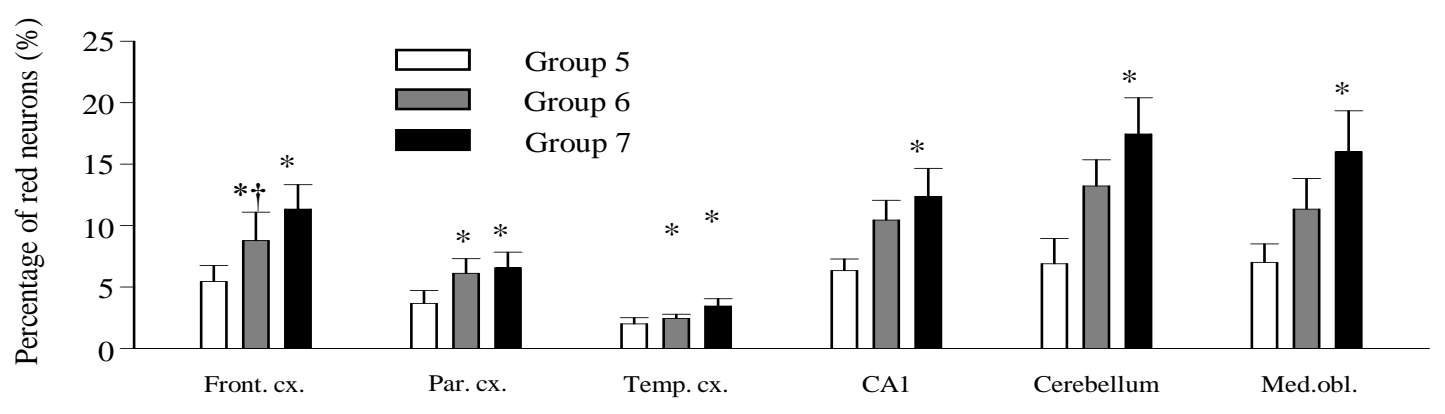

Figure 10. Neuropathological evaluation of different brain regions in the experimental groups 5, 6 and 724 hours after asphyxia. In time controls damaged neurons were rare. Asphyxia elicited a modest but statistically significant increase in the frequency of damaged red neurons in most areas of the cerebral cortex, the CA1 region of the hippocampus, the cerebellum, and the medulla oblongata. There was no significantly elevated neuronal damage in the caudate nucleus, the occipital cortex, and other assessed hippocampal areas (data are not plotted). In most regions $\mathrm{H}_{2}$ ventilation had a small neuroprotective effect. $\mathrm{p}<0,05 *$ versus time controls (group 5), $\dagger$ versus asphyxia (group 6). 


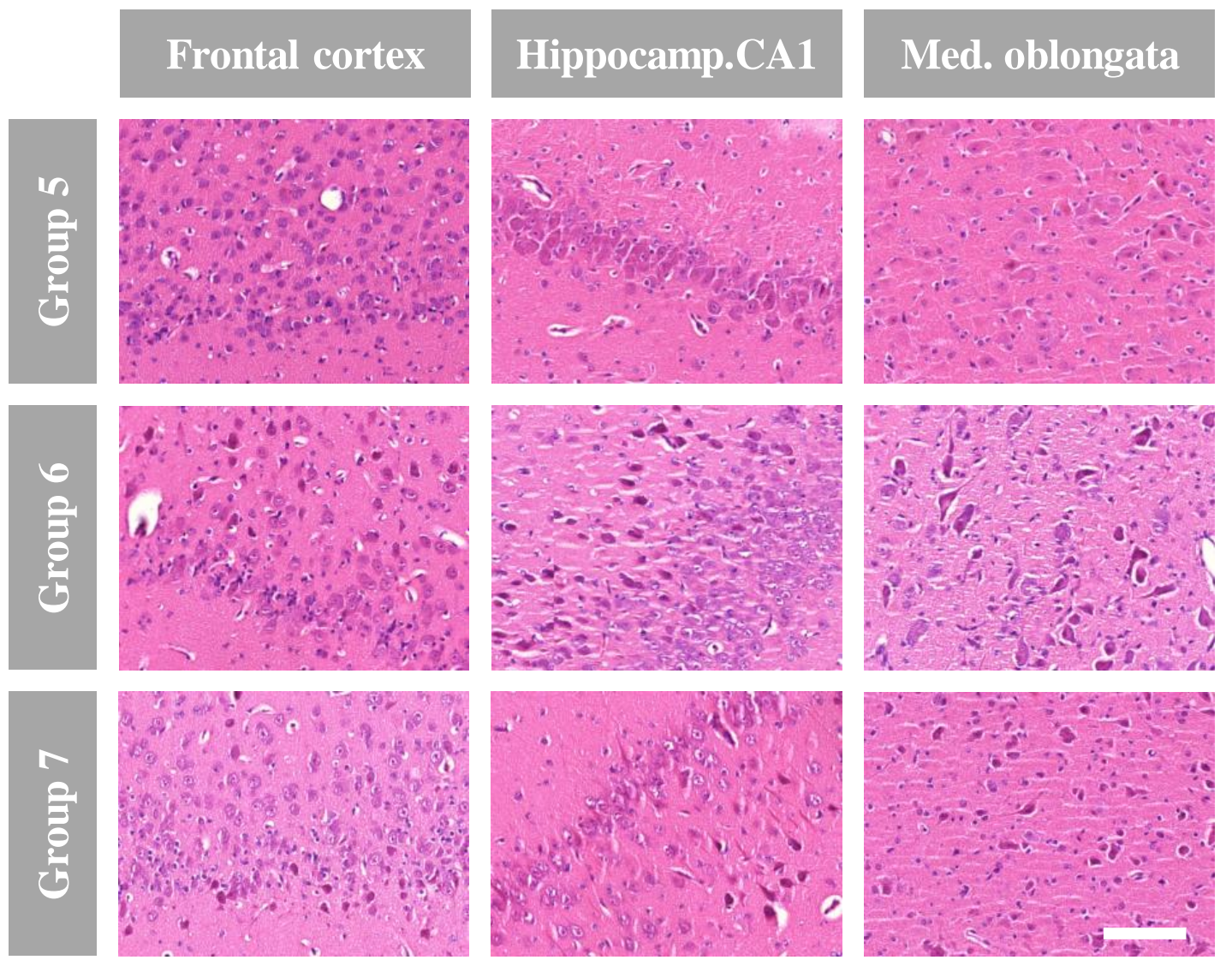

Figure 11. Representative photomicrographs of frontal cortex, CA1 region of hippocampus and medulla oblongata shoving neuronal damage after 24 hours of survival. Magnification 20X, scale bar: $100 \mu \mathrm{m}$.

\section{MAP-2 density}

MAP-2 immunoreactivity was present in the cortex, hippocampus, basal ganglia, thalamus and brainstem, both in perikarya and the dendrites.

Asphyxia did not result in significant change in MAP-2 immunoreactivity in any tested brain region 24 hours

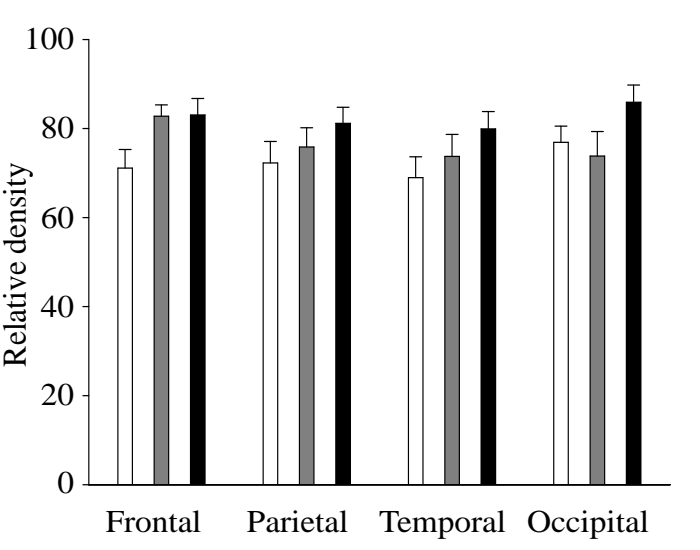

Group 5

following asphyxia (Figure 12.).

Figure 12. MAP-2 density after 24 hours of survival. In the assessed regions there was no difference in relative density among experimental groups. 


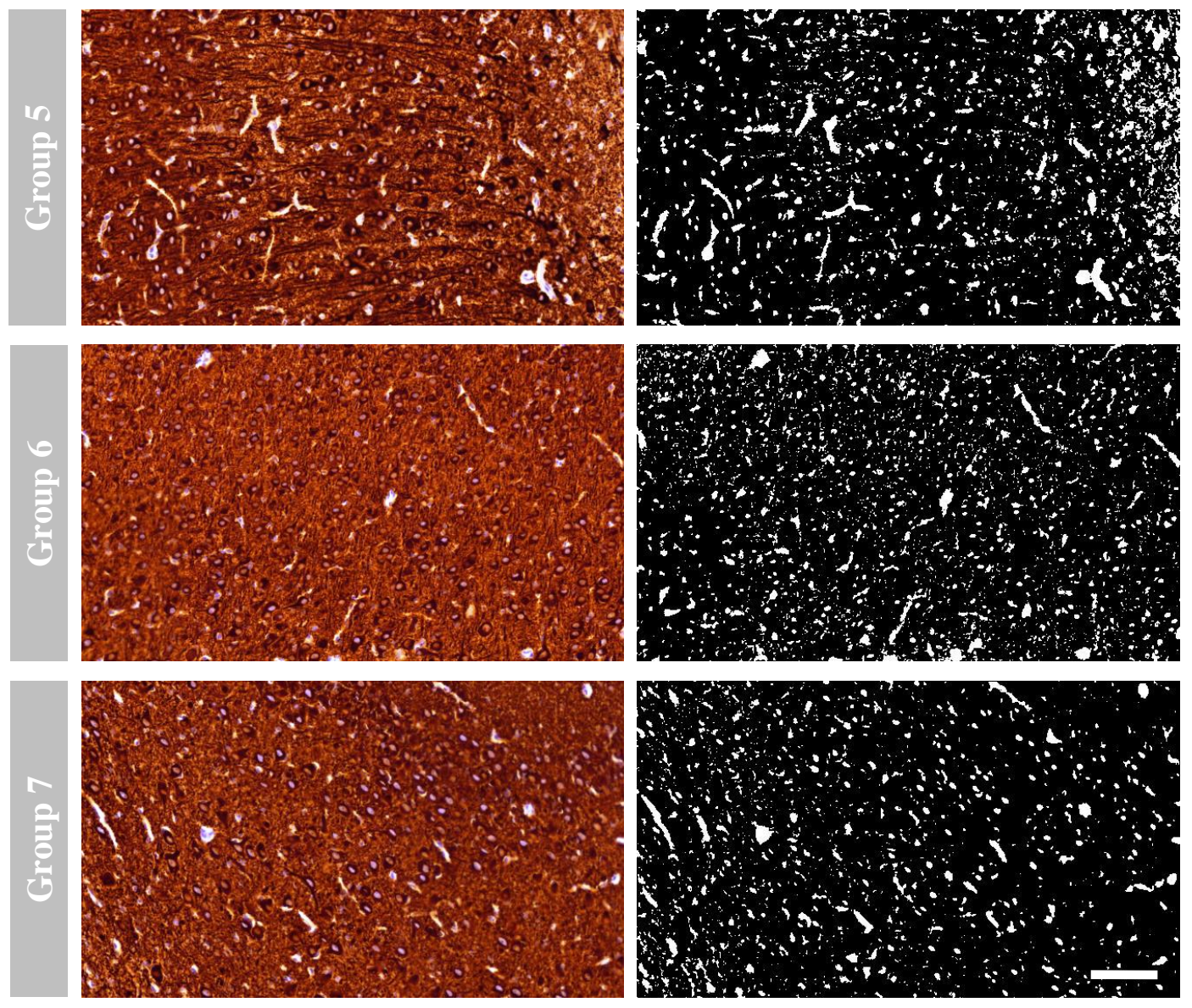

Figure 13. Representative photomicrographs of the MAP-2 immunohistochemistry in the frontal cortex 24 hours following asphyxia (left panels) and the same regions after conversion into the black/white images thresholded at the same level (right panels). Magnification 20X, scale bar represents $100 \mu \mathrm{m}$.

\section{LSI/LASCA studies on the cortical microcirculation}

In group 8, the cortical microcirculation and CR were assessed with LASCA. Laserspeckle contrast images (LSI) analyzed with LASCA showed unchanged parenchymal perfusion, pial arteriolar diameters and flow velocity during $\mathrm{H}_{2}-\mathrm{RA}$ ventilation. Ventilation with 5\% and 10\% CO2 elicited graded hypercapnia and acidosis similar to those levels obtained in the previous studies: arteriolar $\mathrm{pCO}_{2}$ increased from $28 \pm 3 \mathrm{mmHg}$ to $47 \pm 5^{*}$ and $65 \pm 7 * *$, arterial $\mathrm{pH}$ decreased from $7.41 \pm 0.03$ to $7.34 \pm 0.03 *$ and $7.24 \pm 0.05 * *$ respectively; $\mathrm{p}<0.05$, * versus baseline, ** versus baseline and smaller hypercapnia grade). Graded hypercapnia elicited dose-dependent pial arteriolar vasodilation (Figure 14A), and LASCA could show the increased velocity of blood flow in dilated arterioles (Figure 14B). 
Application of NMDA induced a marked increase in pial arteriolar diameters, but no change in arteriolar flow velocity compared to baseline level. However, parenchymal perfusion significantly increased in response to both hypercapnia and NMDA, in accordance with the calculated increases in arteriolar flow (Figure 14C and D). Both doses of NA resulted in significant constriction of pial arterioles similarly to the velocity of blood flow in the constricted arterioles indicating a greatly reduced pial arteriolar flow. Although NA also significantly reduced parenchymal flow velocities reflecting decreased cortical blood flow, this change appears to be only $\sim 55-60 \%$ of the reflective change in the pial arteriolar flow. Asphyxia resulted in severe hypotension, hypoxia, hypercapnia and acidosis; MABP decreased from $70 \pm 5$ to $<40 \mathrm{mmHg}, \mathrm{pO}_{2}$ values decreased from $89 \pm 14$ to $8 \pm 2 * \mathrm{mmHg}, \mathrm{pCO}_{2}$ increased from $30 \pm 4$ to $120 \pm 10 * \mathrm{mmHg}$, and $\mathrm{pH}$ decreased from $7.43 \pm 0.02$ to $6.76 \pm 0.10^{*}$. During asphyxia the arteriolar diameters were relatively unchanged, but there was a severe decrease in arteriolar flow velocity. There was similar degree of severe cortical hypoperfusion shown by decreased low velocity over the parenchyma in accordance with the reduction of calculated arteriolar flow (Figure 14C and D). 


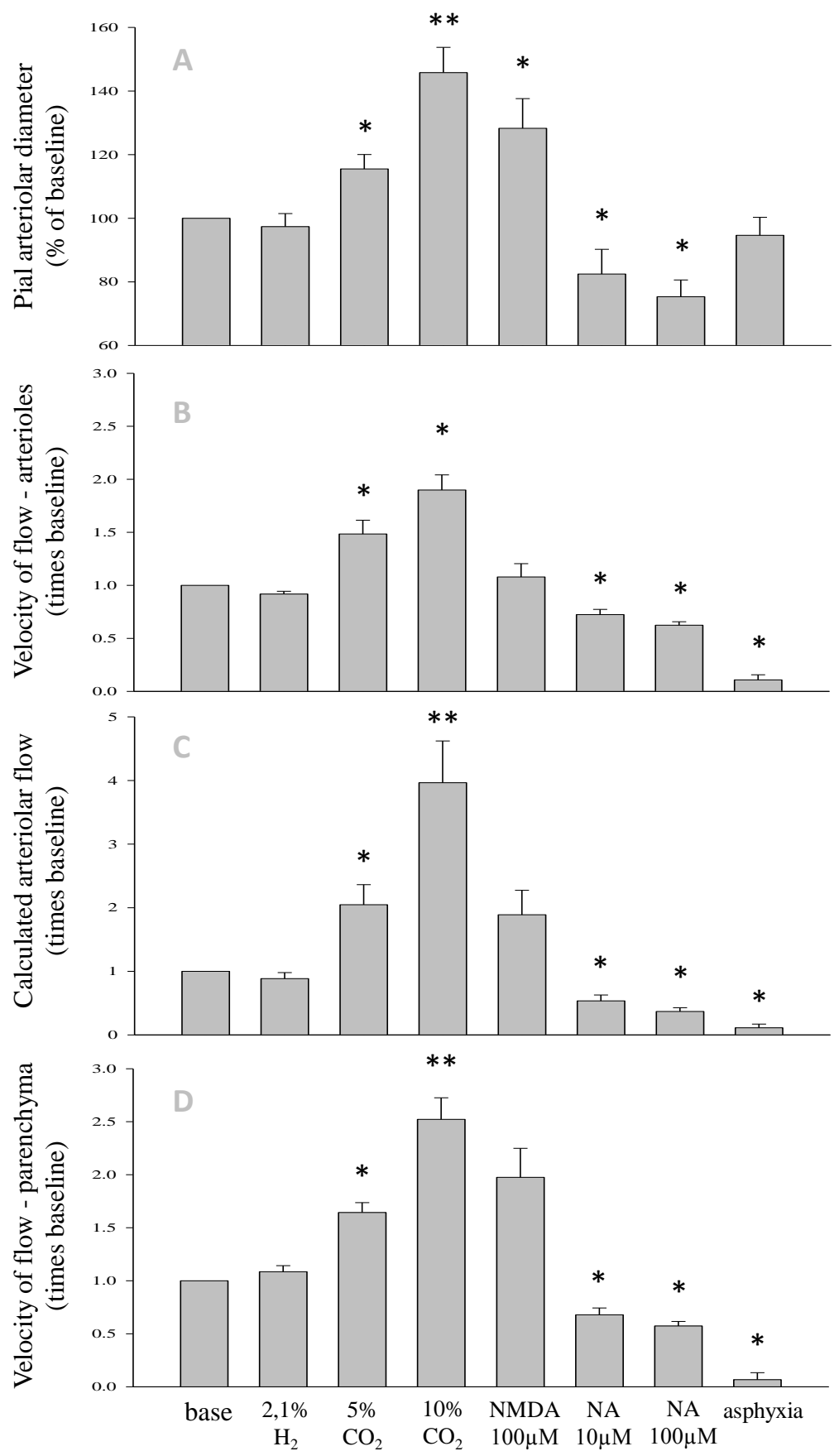

Figure 14. Panel A: Pial arterioles showed no change to $2.1 \%$ hydrogen gas ventilation but dose-dependent vasodilation to hypercapnia. NMDA also resulted in significant pial arteriolar dilation. Arterioles were significantly constricted by both doses of NA but showed relatively no change to asphyxia. Panel $\mathrm{B}$ : The flow velocity was determined using LASCA in the regions of interests over pial arterioles from speckle contrast images. Hypercapnia elicited significant increase, in turn NA and asphyxia significant decrease in the velocity of flow in the pial arterioles. Panel C: changes in arteriolar blood flow were calculated from the changes in pial arteriolar diameters and flow velocity, and plotted. Panel D: The flow velocities in the regions of interests over parenchymal areas were determined as described for Panel B. Flow velocity values indicate significant increases in parenchymal perfusion in response to hypercapnia and NMDA, but significant decreases in response to NA and asphyxia. $\mathrm{p}<0.05, *$ versus respective baselines before the stimulation, $* *$ versus respective baseline values and smaller dose of respective stimulus. 


\section{Discussion}

There are several major findings of the study:

1. The cerebrocortical microcirculation of newborn piglets is characterized by severe neurovascular dysfunction as late as 1 day after asphyxia shown by altered pial arteriolar responses both to endothelial and to neuronal-vascular stimuli.

2. The studied pial arteriolar responses have been demonstrated to significantly contribute to determining local blood flow, since pial arteriolar vasodilation or vasoconstriction are reflected in respective increases or decreases in parenchymal perfusion proven by the novel LSI/LASCA method in our model.

3. $\mathrm{H}_{2}$-supplemented ventilation can be applied safely to newborn pigs and per se does not affect baseline cerebrocortical blood flow, CR, neuronal activity (aEEG activity pattern) or microscopic morphology of the brain.

4. Ventilation with gas containing $\mathrm{H}_{2}$ after asphyxia preserves neurovascular unit function both in the acute period and after $24 \mathrm{~h}$ survival, it also protects the brain from A/R-induced early neuronal injury. Furthermore, $\mathrm{H}_{2}$-ventilation keeps the vital parameters within physiological range, and cause faster recovery in brain electrical activity (aEEG). These findings support the hypothesis that molecular $\mathrm{H}_{2}$ is neuroprotective in this large animal model of HIE.

5. COX-2 expression is widespread in cortical neurons, however, its frequency is low or negligible in the subcortical brain regions in newborn pigs. Cortical COX-2 immunopositive neurons were approximately two times more numerous in the frontoparietal cortex as compared to the temporo-occipital region. $\mathrm{H}_{2}$-supplemented ventilation similarly to asphyxia did not alter neuronal COX-2 expression after 4 hours of survival. This pattern of COX-2 expression can affect the relative importance of COX-2 involvement in the pathophysiology of HIE in different cerebrocortical regions.

The high burden on the society imposed by HIE-affected children necessitated the development of several animal models to help us understanding the pathophysiology of this disease. Among the rodent and other big animal models, the newborn piglet has emerged as perhaps the most valuable large animal model. This species has several advantages including similar brain developmental stage as that of 36-38 weeks human baby with comparable maturity of other body systems. Its relatively large body size allows easy instrumentation and 
monitoring of physiological variables. Our laboratory has accumulated great experience with this species in the last 15 years. Several colleagues have repeatedly shown that hypoxic/ischemic stress attenuates neurovascular reactivity that may result in severe neuronal damage $[62,69,94,106,107]$. However, the duration of these experiments did not allow the follow-up of the animals longer than 4-6 hours. Furthermore, the available experimental instrumentation did not permit to focus on key issues required for long-term experiments: sterile catheters and surgical tools, pulsoximetry, rigorous core temperature control using servo-feedback, and multiple precision syringe pumps for appropriate administration of drugs and fluids - to name a few. Since the neuronal damage leading to HIE is not limited only to the acute phase of reoxygenation period, but it further progresses in the subacute phase associating with the secondary energy failure developing approximately 12-24 hours after the hypoxic/ischemic stress [108], it was urgent to overcome the technical obstacles in order to be able to extend the survival time to at least 24 hours.

The establishment of a longer-term survival animal model for the detection of delayed neurovascular and neural alterations following birth asphyxia has called for major changes. All the modifications made in the experimental protocol including the used drugs and equipments were in accordance with the protocols used currently in neonatal intensive care units following birth asphyxia [109]. In addition, surgery has been performed with sterile instruments to maintain aseptic conditions supplemented with intravenous administration of antibiotics to prevent infections during the survival time. The catheterisation of the femoral artery was abandoned since it produced critical ischemia in the affected extremity over the elongated observation time. In parallel to these changes, the monitoring of homeostatic parameters has been extended: in addition to the non-invasive measurement of blood pressure, and regular detection of blood gas parameters, we have now placed ECG electrodes for continuous ECG detection, pulsoximeter to monitor oxygen saturation, and blood glucose levels were also monitored. These methodological innovations together made it possible to precisely regulate the fluid intake, the ventilation parameters, and to administer drugs achieving stable and satisfactory macrohemodynamic status.

Another major improvement was the introduction of aEEG monitoring that provided valuable information on the severity of asphyxia and also on the gradual restoration of neuronal function. [109] [110]. The tight control of core temperature also mandated the reduction of asphyxia duration from the previously used 10 minutes to 8 minutes. This was necessary because the mortality rate of the $10 \mathrm{~min}$ long asphyxia under the new experimental 
conditions was unacceptably high in the pilot experiments. Core temperature is well-known to affect the outcome of hypoxic-ischemic stress, and likely any undetected decrease in body temperature for instance during the asphyxia might have altered outcome due to the lack of a servo-controlled heating system.

The major outcome measure of CR in our studies was the demonstration of pial arteriolar responses to various vasoactive stimuli. In most common animal models and in humans as well, large cerebral arteries and pial arterioles have substantial tone and react to diverse vasodilator stimuli [111-113]. The contribution of pial arterioles to local vascular resistance is unequivocally accepted, however, the precise parenchymal flow changes in response to pial arteriolar vasodilatory or vasoconstrictor responses for a long time remained unknown. There were efforts more than thirty years ago to determine cortical blood flow (CoBF) changes by simultaneously determining vascular cross sectional area and flow velocity in cats and dogs, however the procedure required quite difficult surgical procedure [114]. The cerebrovascular circulation has been demonstrated to be unique in that aspect that large cerebral arteries and arterioles on the surface of the brain account for as much as 50-60\% of total cerebral vascular resistance. Local intravascular pressure is approximately half of systemic blood pressure in the cerebrocortical pial arterioles at their entry into the parenchyma. According to these findings, cerebral arteries and pial arterioles make major contributions to the regulation of cerebral blood flow and local microvascular perfusion pressure [115, 116].

In the present studies, pial arteriolar diameters were determined using a relatively old technique: the implantation of a closed cranial window and measurement of internal vascular diameters with intravital microscopy. This method has been scrupulously applied previously to demonstrate the selective vulnerability of certain responses to hypoxic/ischemic stress. Therefore, the alterations of CR to these vulnerable stimuli can be can be used as sensititive indicators of neurovascular unit dysfunction, and can also be utilized when assessing neuroprotective treatment strategies after hypoxic/ischemic stress [85, 94]. Our present studies focused at two of these vulnerable stimuli: hypercapnia- and the glutamate-receptor agonist NMDA-induced pial arteriolar vasodilation. Furthermore, we assessed the effect of NA to study a major vasoconstrictor mechanism as well.

Hypercapnia induced pial arteriolar vasodilation has been extensively studied in the piglet. $10 \% \mathrm{CO}_{2}$ ventilation dilate the arterioles by $40-50 \%$ that approximately doubles the arteriolar cross sectional area allowing similar increase in flow. Some quantitative studies found that 
$\mathrm{CO}_{2}$ ventilation increased cortical blood flow by $\sim 300 \%$ in anesthetized or even awake piglets [117-119]. In contrast to studies using quantitative method for CBF measurement, in previous studies from our laboratory using Laser-Doppler flowmetry the data did not indicate such large increases in cortical blood flow; it increased only by $40 \%$ at the same level of hypercapnia [106]. This difference shows significant uncertainty of the indirect LDF method highlighting the necessity of an accurate non-invasive method which can be simply applied. In our study performed with LASCA, we observed similar pial arteriolar dilation to previous studies, and the LASCA analysis of parenchymal regions of interest obtained during the same level of hypercapnia showed a $250 \%$ increase in microvascular flow velocity. Furthermore, we observed a significant increase in flow velocity in the dilated pial arterioles. These data combined suggest that the calibre changes in pial arterioles have indeed profound effects on $\mathrm{CoBF}$, suggesting that the true increases in $\mathrm{CoBF}$ to hypercapnia are likely even underestimated by taking the pial arteriolar dilation into account only. Our LASCA studies, however, confirm that relevant conclusions concerning the effects of vascular reactivity changes on cortical perfusion can be drawn by studying pial arteriolar responses. The development and testing of the LSI imager was simultaneous with our studies on delayed neurovascular unit dysfunction, so unfortunately we were unable to use this equipment in those experiments. However, future studies definitely can yield important new data on the contribution of different cortical microvascular segments to the altered cerebrovascular regulation after asphyxia, observed in the present studies only in the pial microvessels.

Hypercapnia-induced vasodilation is the most commonly used stimulus to test the CR and has been extensively studied in the piglet and other species. In newborn pigs, hypercapniainduced pial arteriolar dilation requires intact endothelium [84]. The response is associated with increase in cerebral synthesis of dilator prostanoids, and the prostanoids appear to be endothelial in origin [120]. Hypercapnia-induced vasodilation is vulnerable to hypoxia/ischemia, however supplementation of arachidonic acid restores the vasodilation [121]. Accordingly, hypoxia/ischemia seems to reduce the hypercapnia-induced vasodilation of pial arterioles through endothelial damage. Although the majority of data suggest the main involvement of endothelium, the role of other cell types cannot be excluded, since other cellular components (neural/glial) can also contribute to hypercapnia-induced dilation in other experimental models $[122,123]$.

Glutamate is abundant in the mammalian nervous system and especially in the brain where it is the most abundant excitatory neurotransmitter, and also the precursor for GABA 
the main inhibitory neurotransmitter [124]. Glutamate activates a number of ionotropic and metabotropic receptors on neurons and astrocytes. Glutamate and its agonists elicit dosedependent vasodilation in the intact cerebral circulation when applied in vivo topically that was firstly shown in newborn pig $[82,85]$. The vasoactive effects of glutamate are exerted via activation of any of the ionotropic receptors, however topical application to the brain surface of the cerebral cortex appears to dilate arterioles predominantly via NMDA receptor activation [125]. The activation of neuronal NMDA receptors leads to latter activation of a population of nNOS positive neurons and NO production via local neuronal connections. The neuronally derived NO then diffuses to the vascular smooth muscle to increase in cGMP level and dilate the pial arterioles $[61,65,86,125]$.

NMDA-induced vascular dilation was repeatable several times and even prolonged topical application did not appear to damage the cortex in vivo or affect pial responsiveness to other stimuli $[68,82,126]$. In contrast, NMDA-induced vasodilation has been shown to be vulnerable to periods of global cerebral hypoxia/ischemia [68]. Most of the studies strongly suggest the causative role of reactive oxygen species in attenuation of NMDA-induced pial arteriolar dilation after hypoxia/ischemia [127]. Topical application of ROS scavengers preserves cerebral arteriolar dilator responses to NMDA after hypoxia/ischemia in piglet [61].

Cerebral resistance vessels have extensive sympathetic innervation, limiting cerebrovascular dilation during arterial hypertension, hypoxia, hypercapnia, and hemorrhagic states, attenuating disruption of BBB during hypertension, and contributing to development and maintenance of vascular morphology [68]. It appears that increase in sympathetic neural activity increases cerebral vascular tone and by interaction with the myogenic properties of the smooth muscle cells result in cerebral vasoconstriction and enhanced cerebral autoregulation [128]. Albeit it has been known that there are important differences among species in cerebrovascular responses to alpha-adrenergic stimuli, topical application of NA exerts near-maximal constriction in most of mammalian animals including newborn pigs $[129,130]$. It has been also shown that there also are differences among species with respect to predominant alpha-adrenoreceptor subtypes in cerebral resistance vessels. Alpha $2^{-}$ adrenoreceptors predominate in pial arterioles of piglets, cats, dogs and cows [131-134]. Sympathetic nerve stimulation also constricts cerebral arterioles via alpha 2 -adrenoreceptor subtype in piglet. It has also been shown that exogenous NA also constricts pial arterioles via alpha 2 -adrenoreceptors $[131,135]$. There are not just species but also age-related differences in action of exogenous NA, thus low concentrations of NA dilated cerebral arteries while 
higher doses caused constriction in subadult pigs [136]. Similarly to the differences in different adrenoreceptor subtype densities there are striking differences in action of other common substances confirming the unique status of perinatal cerebrovascular physiology. For instance, the response of the newborn pig pial circulation to cholinergic stimulation is primarily constriction in contrast to well-known dilator response exerted in other vascular beds [137].

The different vasoactive stimuli allow the examination of components of neurovascular unit due to the different mechanisms of action and help understanding the pathophysiology of hypoxic/ischemic damages. Hypercapnia-induced vasodilation requires intact endothelium confirmed by the observation that hypercapnia evokes cerebral vasodilation not only in vivo, but also in isolated, denervated vessels [138]. Based on these findings the function of neuronal and glial components in this vascular response seems to be minor, and hypoxia/ischemia appears to reduce hypercapnia-induced dilation of pial arterioles primarily through endothelial damage in piglets. Asphyxia significantly attenuated CR to hypercapnia in the acute period of survival. $\mathrm{H}_{2}$-supplemented ventilation preserved $\mathrm{CR}$ to hypercapnia 1 hour after $\mathrm{A} / \mathrm{R}$ indicating intact endothelial function in the early reventilation period. Endothelial cells are critical not only to CR but also to the integrity of the blood-brain barrier; the latter being crucial to prevent ischemic brain damage [139]. The intact endothelial function in the early survival period may have further beneficial effects by protracting the near-normal function of the BBB.

NMDA-induced vasodilation has been repeatedly shown to be sensitive to global cerebral ischemia/reperfusion, and CR to NMDA $(100 \mu \mathrm{M})$ is attenuated by $50 \% 1 \mathrm{~h}$ after $10 \mathrm{~min}$ ischemia $[68,85]$. Interestingly, we have not observed a decrease in CR to NMDA 1 hour after $10 \mathrm{~min}$ of asphyxia. The only study in the literature investigating the effect of asphyxia on NMDA-induced vasodilation reported "altered" CR to NMDA based on progressively increasing CR to NMDA in the early reventilation period [83]. However, in that study, CR to NMDA was not determined before asphyxia. Furthermore, the vasodilation to $10 \mu \mathrm{M}$ NMDA used in that study corresponds with our later findings with this dose of NMDA under normoxic conditions [65]. Thus, it is conceivable that $A / R$ represents a less severe stress in the acute period than global ischemia/reperfusion, and CR to $100 \mu \mathrm{M}$ NMDA does not change appreciably 4 hours following using this stress. 
The study examining acute changes in CR has got several important limitations. The changes in CR were demonstrated following only a short observational period that can be altered by development of reperfusion injury. The cerebral metabolism may recover following the initial phase of energy failure and reperfusion, but can also deteriorate due to the secondary energy failure phase. This phase starts usually within 6-24 hours after the initial insult and it results in progressive neuronal damage due to mitochondrial dysfunction and activation of apoptotic cascade. The exact duration of this delayed phase cannot be precisely ascertained described period, although it seems to contribute to neuronal damage increase in the first 24-48 hours, and has a significant impact to neurodevelopmental outcome at 1 year and 4 years after insult [140]. The importance of this delayed period of secondary neuronal damage justified and necessitated the extension of the observation period to $24 \mathrm{~h}$ in our subsequent studies.

Previously, only two early studies reported decreased CR to hypercapnia and hypotension 1 day after cerebral ischemia in newborn piglets [70,81]. We are not aware of any other studies that so far assessed the delayed cerebral microvascular effects of this duration of hypoxic/ischemic stress. However, the interpretation of these data is somewhat problematic for several reasons. First, in these studies, $20 \mathrm{~min}$ of no flow global cerebral ischemia was induced in unanesthetized animals by elevating intracranial pressure above the arterial pressure by infusion of aCSF through a surgically previously implanted hollow bolt. The clinical relevance of this long and complete selective brain ischemia is difficult to establish. Second, 30-60 min after the insult, the comatose piglets were allowed to breathe spontaneously and were fed with milk substitute by gavage, no analgesia or other supportive therapy was provided. Blood pressure, tissue oxygenation and body temperature were not monitored and potential derangements in these parameters over the course of the $24 \mathrm{~h}$ survival period could occur and contribute to the observed attenuation of CR. Furthermore, confounding data emanated from a more recent set of studies, in which the attenuated CR to numerous stimuli (hypercapnia, NMDA, the ATP-sensitive potassium channel agonist aprikalim, and the prostacyclin analogue iloprost) spontaneously recovered 2-4 hours after hypoxic/ischemic stress $[62,63,68]$. In these studies, global cerebral ischemia was also performed with the same technique, however, in anesthetized animals and the duration of the anoxic stress was only $10 \mathrm{~min}$. The question whether the attenuation of CR lasts only 1-2 hours or persists as long as 24 hours depending on the severity of the hypoxic/ischemic stress (10 vs. $20 \mathrm{~min}$ ) or on the presence of anesthesia, remained unresolved. 
In the 1-day survival animals a huge difference in CR between normoxic time controls and asphyxiated piglets were observed to hypercapnia and NMDA, and these differences could not be attributed to alterations in hemodynamics, blood chemistry or body temperature. Before the implantation of the closed cranial window for CR measurements, the anaesthesia was switched to $\alpha$-chloralose in order to make the results comparable to acute changes. Indeed, the magnitude of pial arteriolar diameter changes in response to these stimuli was virtually identical to those determined in the acute model of brain asphyxia [65, 69, 141]. Although both, the endothelium-dependent hypercapnia-induced vasodilation and the neuronal-vascular dependent NMDA-induced vasodilation were attenuated, thus, in contrast to the acute endothelial damage, the delayed impairment of CR was found to involve both the neuronal and the microvascular elements of the neurovascular unit vulnerable to hypoxicischemic stress.

The efficacy of early $\mathrm{H}_{2}$ administration to fully (hypercapnia) or at least partially (NMDA) preserve neurovascular function 1 day after the insult underscores the possibility that ROS-inflicted damages to the neurovascular unit in the early reventilation period trigger the development of delayed neurovascular dysfunction perhaps similar to the delayed energy failure observed also in this period. A somewhat unexpected finding of the studies made on subacute piglet model of birth asphyxia was that the hypoxia/ischemia insensitive NAinduced vasoconstriction [81] was significantly less in the $\mathrm{H}_{2}$ treated animals. We are unsure if this slight difference has any biological significance, the little higher steady state pial arteriolar diameter values could perhaps be due to a better activation of compensatory vasodilatory mechanisms to prevent cortical hypoperfusion after asphyxia in these animals.

To confirm the neuronal damage found by functional examination of the neurovascular unit quantitative neuropathologic examination was performed in numerous brain regions following both observational periods.

This model of birth asphyxia showed significant difference to methods used previously describing significant neuronal changes $[62,68]$. Not only the duration of the hypoxic period was $20 \%$ shorter, but in this model cortical blood flow was not abruptly and fully stopped, but more gradually decreased over the course of $4-5 \mathrm{~min}$ to $\sim 20 \%$ of baseline values as determined previously with laser Doppler flowmetry [94]. Despite the shorter asphyxic period our observations made on the acute model of brain asphyxia showed remarkable neuronal damage following 10 minutes of asphyxia that can be significantly decreased by the 
inhalation of $\mathrm{H}_{2}$-RA. Our laboratory has previously shown the neurotoxic effect of $100 \%$ oxygen ventilation compared with RA ventilation after the same A/R stress used in this study [94]. The degree of neuronal injury was similar in the RA ventilated control groups in both studies, albeit in this study we used a quantitative cell counting approach in contrast to the semiquantitative scoring system used in the previous study. Thus, our simple acute A/R model of perinatal asphyxia is capable to detect both neuroprotective and neurotoxic effects related to the changes in the composition of gas mixture used for ventilation. We emphasize that we observed a beneficial effect of $\mathrm{H}_{2}$ - $\mathrm{RA}$ ventilation in virtually all brain regions studied in the early survival period. In our study was observed a mild decrease in CoBF during the 4 hours of $\mathrm{H}_{2}$-RA ventilation that may also contribute to its early neuroprotective effect after A/R by limiting luxury oxygen delivery to the metabolically compromised brain parenchyma. Our observations made on the acute model of brain asphyxia were the first in demonstrating the early neuroprotective effect of $\mathrm{H}_{2}-\mathrm{RA}$ ventilation in a large animal model, however the observed early neuroprotective effect of $\mathrm{H}_{2}-\mathrm{RA}$ ventilation is in accordance with previous data reporting neuroprotection by $2.1 \% \mathrm{H}_{2}$ gas in a neonatal rat hypoxia/ischemia model [100] and also in an adult rat stroke model [98].

Compared to the study with acute survival period, in delayed study we used a milder hypoxic/ischemic insult: 8 min asphyxia. Indeed, the recovery of the brain electrical activity on the aEEG and the mild neuronal damage detected with histopathology confirmed this notion. We performed immunohistochemistry of the neuronal cytoskeletal protein microtubule associated protein (MAP-2) in order to determine the so called MAP-2 score established by Lingwood et al. [104]. MAP-2 is involved in maintaining the structural integrity of neuronal cytoskeleton. Reduction in MAP-2 immunoreactivity is a sensitive early marker of neuronal injury and the labelling intensity correlates with severity of hypoxic insult and with the spatial distribution of the injury $[142,143]$. In our study we detected no statistically significant differences among the groups also suggesting a relatively minor injury.

The mild histological change concerning the number of damaged red neurons observed 24 hours following 8 minutes of asphyxia is notably less than our results in acute survival study. This raises a question; whether all the red neurons counted 4 hours following 10 minutes of asphyxia displaying hyperchromatic cytoplasm, pyknotic nucleus and dramatic compaction are irreversibly damaged neurons, or they can belong to a much debated phenotype of so-called dark neurons. Dark neurons can be produced by both in vivo, and post mortem mechanical injury, status epilepticus, hypoglycaemia and ischemia [144]. According to 
electronmicroscopic observations, the ultrastructural elements of the dark neurons are intact, but are compacted, with increased electrodensity [145]. In our studies we could detect these electronmicroscopic changes in some of the cells in the acute survival groups. Dark neurons may represent cell population at risk that may later recover after the restoration of blood supply and oxygenation [146]. This could explain how the number of hyperchromatic cells is reduced as the survival time increases in the temporal evolution of HIE.

Birth asphyxia is characterized by systemic hypoxemia with hypercapnia. The first compensatory response is the increase in $\mathrm{CBF}$ along with the redistribution of cardiac output to the essential vital organs. During the reoxygenation period, free radical production increases due to enzymatic activation (e.g. cyclooxygenase, xanthine oxidase, lipoxygenase). After hypoxia/ischemia, COX-2-derived prostanoids and superoxide anions have been considered to enhance the neuronal and vascular damage in the CNS, but several studies showed that enhanced COX-2 expression could also be protective in the CNS [147]. COX-2 produces superoxide anions in a 1:1 ratio with $\mathrm{PGH}_{2}$, and $\mathrm{COX}$-derived $\mathrm{ROS}$ have been shown to be important for the generation of oxidative stress following ischemic stress [148, 149]. Furthermore, COX-2 activity has been demonstrated to contribute to the neurovascular dysfunction after hypoxia/global cerebral ischemia in piglets.

COX-2 is known to be induced by anoxic stress, parenchymal and cerebrovascular COX-2 mRNA levels were shown to increase within 0.5-2 hours after global cerebral ischemia in the piglet $[67,150]$. In our study made on acute changes after birth asphyxia, asphyxia was shown to significantly increase the number of damaged neurons after 4 hours, moreover, hydrogen ventilation was shown to partially alleviate the hypoxic/ischemic neuronal damage [141]. However, we could not show statistically significant increases of COX-2 immunopositive neurons, perhaps there was a slight tendency for increased number of positive neurons after asphyxia in the parietal and occipital cortices. This perhaps unexpected result is likely due to the increased turnover rate of COX-2, for instance in cerebral arteries COX-2 mRNA levels increased within $30 \mathrm{~min}$, but increased protein levels were detected only 8 hours after ischemic stress [67]. According to the results of COX-2 immunohistochemistry, the baseline pattern of cerebral COX-2 expression does not significantly change during the first few hours of reoxygenation - in the period when most oxidative stress occurs. 
The role of COX-2 in the mechanism of hypoxic-ischemic injury in the piglet has been virtually exclusively derived from studies on the parietal cortex [64, 85, 148]. Our findings suggest that coincidentally the parietal cortex might be one of the most sensitive regions of the piglet brain to COX-2 inflicted neuronal injury, since COX-2 expression appears to be the most widespread in the neurons of this cortical region. First Dégi et al. [151] examined qualitatively the regional distribution of COX-2 immunoreactivity in the piglet brain, however, the cerebral cortex was only represented by samples from the parietal cortex, thus the regional difference discovered by our study could not be noted. Our findings indicate that COX-2 dependent oxidative stress upon reoxygenation/reventilation after hypoxic/ischemic stress can be more severe in those cortical areas where basal COX-2 expression is significantly higher.

Compared to the cortex, the hippocampus and the subcortical areas studied had low neuronal COX-2 expressions. Dégi et al. [151] reported qualitatively strong COX-2 immunoreactivity in the stained hippocampal neurons, but in our study we found that the percentage of such stained neurons was in fact low. Interestingly, neuronal COX-2 expression appears to have an inverse relationship with regional cerebral blood flow. Indeed, regional blood flow in the midbrain, pons, medulla and cerebellum (expressing low levels of COX-2) is significantly higher as compared to the cortical regions (displaying high COX-2 expression) under normal conditions in piglets [152]. The cortical prostanoids appear to limit cortical blood flow by constricting cerebral arterioles, furthermore the high cortical COX-2 expression appears to be necessary for the expression of prostanoid receptors and coupled signal transduction proteins required for the age-dependent vascular regulation [153, 154]. We previously found that reactive hyperemia after asphyxia was significantly greater in the cerebellum than in the parietal cortex, and these hemodynamic differences were associated with increased vulnerability of the cerebellum but not the cortex to $100 \% \mathrm{O}_{2}$ versus room air ventilation after asphyxia [94]. Our findings suggest that regional hemodynamic difference might exist within the cortex itself that need to be looked at.

Despite the large number of ROS producing resource the antioxidant defences are immature in the neonate that further exacerbates the free radical damage. Free radical and reactive oxygen species production can lead to lipid peroxidation, to DNA and protein damage, or can combine with nitric oxide to form peroxynitrite, which is a highly toxic oxidant $[155,156]$. 
Oxidative stress induced by ROS produced during/after a hypoxic-ischemic episode is a widely accepted pathomechanism of perinatal brain injury [1, 157]. Thus, administration of antioxidant drugs either to decrease ROS production or to neutralize ROS seems to be a simple, straightforward approach to alleviate brain damage. However, the antioxidant drug needs to be present at the ROS level surge in the early reventilation/reperfusion to exert its effect. For example, the xanthine oxidase inhibitor allopurinol was found ineffective when administered to severely asphyxiated term infants $4 \mathrm{~h}$ after birth [158]. The authors speculated that drug administration was too late to successfully target the immediate ROS surge after resuscitation. In fact, in a more recent study, the same research group has found that maternal treatment of in utero asphyxiated infants with allopurinol reduced the concentration of the brain injury marker S-100B in infants with therapeutic allopurinol levels [159]. It has been also shown that $95 \%$ of cord blood samples had target allopurinol concentrations at the moment of delivery [160]. Despite the advantages of maternal treatment, these types of drugs can be used only in suspected cases of fetal hypoxia.

The development of an ideal gas mixture used for the resuscitation of infants affected by perinatal asphyxia may represent an ideal way to implement an instant neuroprotective therapy. The importance of careful selection of inhaled oxygen concentration level is already well established, and the study confirms that addition of $2 \% \mathrm{H}_{2}$ gas may likely confer neuroprotection by combating ROS-inflicted neuronal damage during the early reperfusion/reoxygenation period. This concentration of $\mathrm{H}_{2}(2-2.1 \%)$ is safe because $\mathrm{H}_{2}$ has no risk of flammability below $4.7 \%$ in RA, and this $\mathrm{H}_{2}-\mathrm{RA}$ ventilation protocol yielded $\mathrm{H}_{2}$ concentration of $20 \mathrm{ng} / \mathrm{mL}\left(10^{-5} \mathrm{M}\right)$ in the arterial blood of adult rats, suggesting an effective antioxidant capacity at this dose [98]. Furthermore, other gases may potentially be added to the neuroprotective gas mixture to enhance neuronal survival and function. The anesthetic gas, xenon (50\% inhaled concentration) has been found to augment neuroprotection afforded by hypothermia in the neonatal rat hypoxia/ischemia model [161, 162], and helium (70\% $\mathrm{He} / 30 \% \mathrm{O}_{2}$ ) provided excellent neuroprotection in adult rat stroke models [163-165].

More recently, $\mathrm{H}_{2}$ ventilation has been found to protect against the development of cognitive impairment, cerebral palsy, and brain atrophy determined 1 month after germinal matrix haemorrhage induced in neonatal rats [166], and after subarachnoid hemmorhage in adults [167]. In our acute and subacute studies we demonstrated this neuroprotective effect in a large animal model. We also showed the protective effect of $\mathrm{H}_{2}$ on $\mathrm{CR}$ in the early and the delayed reventilation period. The whole range of the biological effects of $\mathrm{H}_{2}$ is not yet 
known, and it may not be limited to ROS scavenging $[168,169]$, but the antioxidant potential of $\mathrm{H}_{2}$ plausibly explained the observed protection [141], because the mechanism of $\mathrm{CR}$ impairment involves ROS. In the delayed birth asphyxia model $\mathrm{H}_{2}$ ventilation was given for 4 hours starting immediately after the asphyxia and thus stopped 20 hours before the CR measurements excluding the possibility of the direct involvement of $\mathrm{H}_{2}$ on the observed preservation to $\mathrm{CR}$. We believe that this $\mathrm{H}_{2}$ administration regimen would be also a clinically plausible therapy for asphyxiated infants: starting with the resuscitation and ending in a cooling centre where therapeutic hypothermia can be introduced ( $\leq 6$ hours postnatally) [170], affording perhaps some extra neuroprotection. 


\section{Acknowledgements}

I respectfully thank Dr. Ferenc Domoki, who has served both as my professional mentor and supervisor, both as a helping friend. His kindness and patience enabled me to get familiar with basic neuroscience and provided guidance for the continuation of experiments that resulted in the present thesis. I am also grateful for all his thoughtful suggestions during the preparation of the manuscripts and this thesis.

Special thanks to Prof. Ferenc Bari who has introduced me to scientific work.

I wish to express my gratitude to Prof. Gábor Jancsó for making it possible for me to work at the Department of Physiology, Faculty of Medicine, University of Szeged.

I thank Valéria Tóth-Szüki for the accurate and excellent technical support and the friendly atmosphere she created around me all these years. Finally, I would like to say thanks to all my friends, colleagues and my family for all their help and support. 


\section{References}

1. $\quad$ Ferriero, D.M., Neonatal brain injury. N Engl J Med, 2004. 351(19): p. 1985-95.

2. Grow, J. and J.D. Barks, Pathogenesis of hypoxic-ischemic cerebral injury in the term infant: current concepts. Clin Perinatol, 2002. 29(4): p. 585-602, v.

3. Perlman, J.M., Brain injury in the term infant. Semin Perinatol, 2004. 28(6): p. 415-24.

4. Bryce, J., et al., WHO estimates of the causes of death in children. Lancet, 2005. 365(9465): p. 1147-52.

5. Lawn, J., K. Shibuya, and C. Stein, No cry at birth: global estimates of intrapartum stillbirths and intrapartum-related neonatal deaths. Bull World Health Organ, 2005. 83(6): p. 409-17.

6. Fetal and Neonatal Brain Injury. Fourth Edition ed, ed. D.K. Stevenson, et al. 2003, New York: Cambridge University Press.

7. Badawi, N., et al., Antepartum risk factors for newborn encephalopathy: the Western Australian case-control study. Bmj, 1998. 317(7172): p. 1549-53.

8. Graham, E.M., et al., A systematic review of the role of intrapartum hypoxia-ischemia in the causation of neonatal encephalopathy. Am J Obstet Gynecol, 2008. 199(6): p. 587-95.

9. Sarnat, H.B. and M.S. Sarnat, Neonatal encephalopathy following fetal distress. A clinical and electroencephalographic study. Arch Neurol, 1976. 33(10): p. 696-705.

10. Zanelli, S.A., Stanley, D.P., Kaufman, D.A. Hypoxic-Ischemic Encephalopathy. 2015 Aug 12, 2013; Available from: http://emedicine.medscape.com/article/973501-overview\#a0156.

11. Martinez-Biarge, M., et al., Predicting motor outcome and death in term hypoxic-ischemic encephalopathy. Neurology, 2011. 76(24): p. 2055-61.

12. Huang, B.Y. and M. Castillo, Hypoxic-ischemic brain injury: imaging findings from birth to adulthood. Radiographics, 2008. 28(2): p. 417-39; quiz 617.

13. Pressler, R.M., et al., Early serial EEG in hypoxic ischaemic encephalopathy. Clin Neurophysiol, 2001. 112(1): p. 31-7.

14. Hellstrom-Westas, L. and I. Rosen, Continuous brain-function monitoring: state of the art in clinical practice. Semin Fetal Neonatal Med, 2006. 11(6): p. 503-11.

15. Spitzmiller, R.E., et al., Amplitude-integrated EEG is useful in predicting neurodevelopmental outcome in full-term infants with hypoxic-ischemic encephalopathy: a meta-analysis. J Child Neurol, 2007. 22(9): p. 1069-78.

16. Ten, V.S. and D. Matsiukevich, Room air or 100\% oxygen for resuscitation of infants with perinatal depression. Curr Opin Pediatr, 2009. 21(2): p. 188-93.

17. Ambalavanan, N. and W.A. Carlo, Hypocapnia and hypercapnia in respiratory management of newborn infants. Clin Perinatol, 2001. 28(3): p. 517-31.

18. McCann, M.E. and A.N. Schouten, Beyond survival; influences of blood pressure, cerebral perfusion and anesthesia on neurodevelopment. Paediatr Anaesth, 2014. 24(1): p. 68-73.

19. Salhab, W.A., et al., Initial hypoglycemia and neonatal brain injury in term infants with severe fetal acidemia. Pediatrics, 2004. 114(2): p. 361-6.

20. Laptook, A., et al., Elevated temperature after hypoxic-ischemic encephalopathy: risk factor for adverse outcomes. Pediatrics, 2008. 122(3): p. 491-9.

21. Gunn, A.J., Cerebral hypothermia for prevention of brain injury following perinatal asphyxia. Curr Opin Pediatr, 2000. 12(2): p. 111-5.

22. Gunn, A.J. and T.R. Gunn, The 'pharmacology' of neuronal rescue with cerebral hypothermia. Early Hum Dev, 1998. 53(1): p. 19-35. 
23. Azzopardi, D., et al., The TOBY Study. Whole body hypothermia for the treatment of perinatal asphyxial encephalopathy: a randomised controlled trial. BMC Pediatr, 2008. 8: p. 17.

24. Shankaran, S., et al., Evolution of encephalopathy during whole body hypothermia for neonatal hypoxic-ischemic encephalopathy. J Pediatr, 2012. 160(4): p. 567-572 e3.

25. Azzopardi, D.V., et al., Moderate hypothermia to treat perinatal asphyxial encephalopathy. N Engl J Med, 2009. 361(14): p. 1349-58.

26. Jacobs, S.E., et al., Whole-body hypothermia for term and near-term newborns with hypoxicischemic encephalopathy: a randomized controlled trial. Arch Pediatr Adolesc Med, 2011. 165(8): p. 692-700.

27. Simbruner, G., et al., Systemic hypothermia after neonatal encephalopathy: outcomes of neo.nEURO.network RCT. Pediatrics, 2010. 126(4): p. e771-8.

28. Jacobs, S., et al., Cooling for newborns with hypoxic ischaemic encephalopathy. Cochrane Database Syst Rev, 2007(4): p. CD003311.

29. Schulzke, S.M., S. Rao, and S.K. Patole, A systematic review of cooling for neuroprotection in neonates with hypoxic ischemic encephalopathy - are we there yet? BMC Pediatr, 2007. 7: p. 30.

30. Shankaran, S., et al., Childhood outcomes after hypothermia for neonatal encephalopathy. N Engl J Med, 2012. 366(22): p. 2085-92.

31. Goldberg, R.N., et al., Use of barbiturate therapy in severe perinatal asphyxia: a randomized controlled trial. J Pediatr, 1986. 109(5): p. 851-6.

32. Van Bel, F., et al., Effect of allopurinol on postasphyxial free radical formation, cerebral hemodynamics, and electrical brain activity. Pediatrics, 1998. 101(2): p. 185-93.

33. Zhu, C., et al., Erythropoietin improved neurologic outcomes in newborns with hypoxicischemic encephalopathy. Pediatrics, 2009. 124(2): p. e218-26.

34. Ashwal, S. and W.J. Pearce, Animal models of neonatal stroke. Curr Opin Pediatr, 2001. 13(6): p. 506-16.

35. Vannucci, R.C., Experimental models of perinatal hypoxic-ischemic brain damage. APMIS Suppl, 1993. 40: p. 89-95.

36. Vannucci, R.C., et al., Rat model of perinatal hypoxic-ischemic brain damage. J Neurosci Res, 1999. 55(2): p. 158-63.

37. Yager, J.Y., Animal models of hypoxic-ischemic brain damage in the newborn. Semin Pediatr Neurol, 2004. 11(1): p. 31-46.

38. Northington, F.J., Brief update on animal models of hypoxic-ischemic encephalopathy and neonatal stroke. Ilar J, 2006. 47(1): p. 32-8.

39. Duffy, T.E., S.J. Kohle, and R.C. Vannucci, Carbohydrate and energy metabolism in perinatal rat brain: relation to survival in anoxia. J Neurochem, 1975. 24(2): p. 271-6.

40. Ikonomidou, C., et al., Sensitivity of the developing rat brain to hypobaric/ischemic damage parallels sensitivity to $\mathrm{N}$-methyl-aspartate neurotoxicity. J Neurosci, 1989. 9(8): p. 2809-18.

41. Hagberg, H., et al., Animal models of developmental brain injury: relevance to human disease. A summary of the panel discussion from the Third Hershey Conference on Developmental Cerebral Blood Flow and Metabolism. Dev Neurosci, 2002. 24(5): p. 364-6.

42. Rice, J.E., 3rd, R.C. Vannucci, and J.B. Brierley, The influence of immaturity on hypoxicischemic brain damage in the rat. Ann Neurol, 1981. 9(2): p. 131-41.

43. Tuor, U.I., M.R. Del Bigio, and P.D. Chumas, Brain damage due to cerebral hypoxia/ischemia in the neonate: pathology and pharmacological modification. Cerebrovasc Brain Metab Rev, 1996. 8(2): p. 159-93.

44. Vannucci, R.C. and S.J. Vannucci, A model of perinatal hypoxic-ischemic brain damage. Ann N Y Acad Sci, 1997. 835: p. 234-49. 
45. Liu, Y., et al., Hypoxic-ischemic oligodendroglial injury in neonatal rat brain. Pediatr Res, 2002. 51(1): p. 25-33.

46. Vannucci, R.C. and S.J. Vannucci, Perinatal hypoxic-ischemic brain damage: evolution of an animal model. Dev Neurosci, 2005. 27(2-4): p. 81-6.

47. Vannucci, R.C. and J.Y. Yager, Glucose, lactic acid, and perinatal hypoxic-ischemic brain damage. Pediatr Neurol, 1992. 8(1): p. 3-12.

48. Ditelberg, J.S., et al., Brain injury after perinatal hypoxia-ischemia is exacerbated in copper/zinc superoxide dismutase transgenic mice. Pediatr Res, 1996. 39(2): p. 204-8.

49. Raju, T.N., Some animal models for the study of perinatal asphyxia. Biol Neonate, 1992. 62(4): p. 202-14.

50. Richardson, B.S., et al., Fetal cerebral, circulatory, and metabolic responses during heart rate decelerations with umbilical cord compression. Am J Obstet Gynecol, 1996. 175(4 Pt 1): p. 929-36.

51. Harris, A.P., et al., Fetal cerebral and peripheral circulatory responses to hypoxia after nitric oxide synthase inhibition. Am J Physiol Regul Integr Comp Physiol, 2001. 281(2): p. R38190.

52. $\quad$ Derrick, M., et al., The in vitro fate of rabbit fetal brain cells after acute in vivo hypoxia. $\mathbf{J}$ Neurosci, 2001. 21(7): p. RC138.

53. Derrick, M., et al., Preterm fetal hypoxia-ischemia causes hypertonia and motor deficits in the neonatal rabbit: a model for human cerebral palsy? J Neurosci, 2004. 24(1): p. 24-34.

54. Tan, S., R. Bose, and M. Derrick, Hypoxia-ischemia in fetal rabbit brain increases reactive nitrogen species production: quantitative estimation of nitrotyrosine. Free Radic Biol Med, 2001. 30(9): p. 1045-51.

55. Myers, R.E., A unitary theory of causation of anoxic and hypoxic brain pathology. Adv Neurol, 1979. 26: p. 195-213.

56. Inder, T., et al., Non-human primate models of neonatal brain injury. Semin Perinatol, 2004. 28(6): p. 396-404.

57. Tumbleson, E. and L.B. Schook, Advances in Swine in Biomedical Research. 1996: Springer.

58. Rothschild, M.F., A. Ruvinsky, and C.A.B. International, The Genetics of the Pig. 2010: CABI.

59. Thoresen, M., et al., Mild hypothermia after severe transient hypoxia-ischemia ameliorates delayed cerebral energy failure in the newborn piglet. Pediatr Res, 1995. 37(5): p. 667-70.

60. Johnston, M.V., Selective vulnerability in the neonatal brain. Ann Neurol, 1998. 44(2): p. 155-6.

61. Bari, F., et al., Differential effects of short-term hypoxia and hypercapnia on N-methyl-Daspartate-induced cerebral vasodilatation in piglets. Stroke, 1996. 27(9): p. 1634-9; discussion 1639-40.

62. Bari, F., T.M. Louis, and D.W. Busija, Effects of ischemia on cerebral arteriolar dilation to arterial hypoxia in piglets. Stroke, 1998. 29(1): p. 222-7; discussion 227-8.

63. Bari, F., et al., Global ischemia impairs ATP-sensitive $K+$ channel function in cerebral arterioles in piglets. Stroke, 1996. 27(10): p. 1874-80; discussion 1880-1.

64. Domoki, F., et al., Cyclooxygenase-2 inhibitor NS398 preserves neuronal function after hypoxia/ischemia in piglets. Neuroreport, 2001. 12(18): p. 4065-8.

65. Domoki, F., et al., N-methyl-D-aspartate-induced vasodilation is mediated by endotheliumindependent nitric oxide release in piglets. Am J Physiol Heart Circ Physiol, 2002. 282(4): p. H1404-9.

66. Domoki, F., et al., Kainic acid rapidly induces cyclooxygenase (COX)-2 in piglet cerebral cortex. Neuroreport, 2000. 11(16): p. 3435-8. 
67. Domoki, F., et al., Ischemia-reperfusion rapidly increases COX-2 expression in piglet cerebral arteries. Am J Physiol, 1999. 277(3 Pt 2): p. H1207-14.

68. Busija, D.W., et al., Effects of ischemia on cerebrovascular responses to $N$-methyl-Daspartate in piglets. Am J Physiol, 1996. 270(4 Pt 2): p. H1225-30.

69. Domoki, F., et al., Diazoxide preserves hypercapnia-induced arteriolar vasodilation after global cerebral ischemia in piglets. Am J Physiol Heart Circ Physiol, 2005. 289(1): p. H36873.

70. Leffler, C.W., et al., Ischemia alters cerebral vascular responses to hypercapnia and acetylcholine in piglets. Pediatr Res, 1989. 25(2): p. 180-3.

71. Iadecola, C., et al., Delayed reduction of ischemic brain injury and neurological deficits in mice lacking the inducible nitric oxide synthase gene. J Neurosci, 1997. 17(23): p. 9157-64.

72. Iadecola, C., Neurovascular regulation in the normal brain and in Alzheimer's disease. Nat Rev Neurosci, 2004. 5(5): p. 347-60.

73. Lo, E.H., T. Dalkara, and M.A. Moskowitz, Mechanisms, challenges and opportunities in stroke. Nat Rev Neurosci, 2003. 4(5): p. 399-415.

74. Hamel, E., Perivascular nerves and the regulation of cerebrovascular tone. J Appl Physiol (1985), 2006. 100(3): p. 1059-64.

75. Neuwelt, E.A., et al., Engaging neuroscience to advance translational research in brain barrier biology. Nat Rev Neurosci, 2011. 12(3): p. 169-82.

76. Fisher, M., Pericyte signaling in the neurovascular unit. Stroke, 2009. 40(3 Suppl): p. S13-5.

77. Stanimirovic, D. and K. Satoh, Inflammatory mediators of cerebral endothelium: a role in ischemic brain inflammation. Brain Pathol, 2000. 10(1): p. 113-26.

78. Stanimirovic, D.B. and A. Friedman, Pathophysiology of the neurovascular unit: disease cause or consequence? J Cereb Blood Flow Metab, 2012. 32(7): p. 1207-21.

79. Xing, C., et al., Injury and repair in the neurovascular unit. Neurol Res, 2012. 34(4): p. 32530.

80. MacKenzie, E.T., et al., Effects of hemorrhagic hypotension on the cerebral circulation. I. Cerebral blood flow and pial arteriolar caliber. Stroke, 1979. 10(6): p. 711-8.

81. Leffler, C.W., et al., Postischemic cerebral microvascular responses to norepinephrine and hypotension in newborn pigs. Stroke, 1989. 20(4): p. 541-6.

82. Busija, D.W. and C.W. Leffler, Dilator effects of amino acid neurotransmitters on piglet pial arterioles. Am J Physiol, 1989. 257(4 Pt 2): p. H1200-3.

83. Busija, D.W. and M. Wei, Altered cerebrovascular responsiveness to $N$-methyl-D-aspartate after asphyxia in piglets. Am J Physiol, 1993. 265(1 Pt 2): p. H389-94.

84. Leffler, C.W., et al., Light/dye microvascular injury selectively eliminates hypercapniainduced pial arteriolar dilation in newborn pigs. Am J Physiol, 1994. 266(2 Pt 2): p. H623-30.

85. Busija, D.W., et al., Mechanisms involved in the cerebrovascular dilator effects of N-methyld-aspartate in cerebral cortex. Brain Res Rev, 2007. 56(1): p. 89-100.

86. Meng, W., J.R. Tobin, and D.W. Busija, Glutamate-induced cerebral vasodilation is mediated by nitric oxide through N-methyl-D-aspartate receptors. Stroke, 1995. 26(5): p. 857-62; discussion 863.

87. Buonocore, G., et al., Oxidative stress in preterm neonates at birth and on the seventh day of life. Pediatr Res, 2002. 52(1): p. 46-9.

88. Kumar, V.H., et al., Exposure to supplemental oxygen and its effects on oxidative stress and antioxidant enzyme activity in term newborn lambs. Pediatr Res, 2010. 67(1): p. 66-71.

89. Saugstad, O.D., Room air resuscitation-two decades of neonatal research. Early Hum Dev, 2005. 81(1): p. 111-6. 
90. Solberg, R., et al., Resuscitation of hypoxic newborn piglets with oxygen induces a dosedependent increase in markers of oxidation. Pediatr Res, 2007. 62(5): p. 559-63.

91. Vento, M., et al., Resuscitation with room air instead of $100 \%$ oxygen prevents oxidative stress in moderately asphyxiated term neonates. Pediatrics, 2001. 107(4): p. 642-7.

92. Davis, P.G., et al., Resuscitation of newborn infants with 100\% oxygen or air: a systematic review and meta-analysis. Lancet, 2004. 364(9442): p. 1329-33.

93. Saugstad, O.D., S. Ramji, and M. Vento, Resuscitation of depressed newborn infants with ambient air or pure oxygen: a meta-analysis. Biol Neonate, 2005. 87(1): p. 27-34.

94. Domoki, F., et al., Reventilation with room air or 100\% oxygen after asphyxia differentially affects cerebral neuropathology in newborn pigs. Acta Paediatr, 2006. 95(9): p. 1109-15.

95. Munkeby, B.H., et al., Resuscitation with 100\% O2 increases cerebral injury in hypoxemic piglets. Pediatr Res, 2004. 56(5): p. 783-90.

96. Temesvari, P., et al., Impaired early neurologic outcome in newborn piglets reoxygenated with 100\% oxygen compared with room air after pneumothorax-induced asphyxia. Pediatr Res, 2001. 49(6): p. 812-9.

97. The International Liaison Committee on Resuscitation (ILCOR) consensus on science with treatment recommendations for pediatric and neonatal patients: neonatal resuscitation. Pediatrics, 2006. 117(5): p. e978-88.

98. Ohsawa, I., et al., Hydrogen acts as a therapeutic antioxidant by selectively reducing cytotoxic oxygen radicals. Nat Med, 2007. 13(6): p. 688-94.

99. Cai, J., et al., Neuroprotective effects of hydrogen saline in neonatal hypoxia-ischemia rat model. Brain Res, 2009. 1256: p. 129-37.

100. Cai, J., et al., Hydrogen therapy reduces apoptosis in neonatal hypoxia-ischemia rat model. Neurosci Lett, 2008. 441(2): p. 167-72.

101. $\mathrm{Fu}, \mathrm{Y}$., et al., Molecular hydrogen is protective against 6-hydroxydopamine-induced nigrostriatal degeneration in a rat model of Parkinson's disease. Neurosci Lett, 2009. 453(2): p. 81-5.

102. Maynard, D., P.F. Prior, and D.F. Scott, Device for continuous monitoring of cerebral activity in resuscitated patients. Br Med J, 1969. 4(5682): p. 545-6.

103. Busija, D.W., C.W. Leffler, and L.C. Wagerle, Responses of newborn pig pial arteries to sympathetic nervous stimulation and exogenous norepinephrine. Pediatr Res, 1985. 19(11): p. 1210-4.

104. Lingwood, B.E., et al., MAP2 provides reliable early assessment of neural injury in the newborn piglet model of birth asphyxia. J Neurosci Methods, 2008. 171(1): p. 140-6.

105. Briers, J.D. and S. Webster, Laser speckle contrast analysis (LASCA): a nonscanning, fullfield technique for monitoring capillary blood flow. J Biomed Opt, 1996. 1(2): p. 174-9.

106. Domoki, F., et al., Acetazolamide induces indomethacin and ischaemia-sensitive pial arteriolar vasodilation in the piglet. Acta Paediatr, 2008. 97(3): p. 280-4.

107. Lenti, L., et al., PACAP and VIP differentially preserve neurovascular reactivity after global cerebral ischemia in newborn pigs. Brain Res, 2009. 1283: p. 50-7.

108. Lorek, A., et al., Delayed ("secondary") cerebral energy failure after acute hypoxia-ischemia in the newborn piglet: continuous 48-hour studies by phosphorus magnetic resonance spectroscopy. Pediatr Res, 1994. 36(6): p. 699-706.

109. Ioroi, T., et al., Changes in cerebral haemodynamics, regional oxygen saturation and amplitude-integrated continuous EEG during hypoxia-ischaemia and reperfusion in newborn piglets. Exp Brain Res, 2002. 144(2): p. 172-7. 
110. Tichauer, K.M., et al., Cerebral metabolic rate of oxygen and amplitude-integrated electroencephalography during early reperfusion after hypoxia-ischemia in piglets. J Appl Physiol (1985), 2009. 106(5): p. 1506-12.

111. Faraci, F.M. and D.D. Heistad, Regulation of the cerebral circulation: role of endothelium and potassium channels. Physiol Rev, 1998. 78(1): p. 53-97.

112. Fujii, K., D.D. Heistad, and F.M. Faraci, Flow-mediated dilatation of the basilar artery in vivo. Circ Res, 1991. 69(3): p. 697-705.

113. Kidoguchi, K., et al., In vivo X-ray angiography in the mouse brain using synchrotron radiation. Stroke, 2006. 37(7): p. 1856-61.

114. Busija, D.W., D.D. Heistad, and M.L. Marcus, Continuous measurement of cerebral blood flow in anesthetized cats and dogs. Am J Physiol, 1981. 241(2): p. H228-34.

115. Faraci, F.M., Protecting against vascular disease in brain. Am J Physiol Heart Circ Physiol, 2011. 300(5): p. H1566-82.

116. Faraci, F.M. and D.D. Heistad, Regulation of large cerebral arteries and cerebral microvascular pressure. Circ Res, 1990. 66(1): p. 8-17.

117. Bauer, R., et al., Effect of hypoxia/hypercapnia on metabolism of 6-[(18)F]fluoro-L-DOPA in newborn piglets. Brain Res, 2002. 934(1): p. 23-33.

118. Busija, D.W. and C.W. Leffler, Hypothermia reduces cerebral metabolic rate and cerebral blood flow in newborn pigs. Am J Physiol, 1987. 253(4 Pt 2): p. H869-73.

119. Brubakk, A.M., W. Oh, and B.S. Stonestreet, Prolonged hypercarbia in the awake newborn piglet: effect on brain blood flow and cardiac output. Pediatr Res, 1987. 21(1): p. 29-33.

120. Hsu, P., M. Shibata, and C.W. Leffler, Prostanoid synthesis in response to high CO2 in newborn pig brain microvascular endothelial cells. Am J Physiol, 1993. 264(5 Pt 2): p. H1485-92.

121. Leffler, C.W., et al., Topical arachidonic acid restores pial arteriolar dilation to hypercapnia of postischemic newborn pig brain. Am J Physiol, 1992. 263(3 Pt 2): p. H746-51.

122. Xu, F., T. Zhou, and D.T. Frazier, Purkinje cell degeneration elevates eupneic and hypercapnic ventilation in rats. Cerebellum, 2004. 3(3): p. 133-40.

123. Wang, Q., et al., Possible obligatory functions of cyclic nucleotides in hypercapnia-induced cerebral vasodilation in adult rats. Am J Physiol, 1999. 276(2 Pt 2): p. H480-7.

124. Petroff, O.A., GABA and glutamate in the human brain. Neuroscientist, 2002. 8(6): p. 562-73.

125. Faraci, F.M. and K.R. Breese, Nitric oxide mediates vasodilatation in response to activation of $N$-methyl-D-aspartate receptors in brain. Circ Res, 1993. 72(2): p. 476-80.

126. Philip, S. and W.M. Armstead, NMDA dilates pial arteries by KATP and Kca channel activation. Brain Res Bull, 2004. 63(2): p. 127-31.

127. Girouard, H. and C. Iadecola, Neurovascular coupling in the normal brain and in hypertension, stroke, and Alzheimer disease. J Appl Physiol (1985), 2006. 100(1): p. 328-35.

128. Purkayastha, S. and P.B. Raven, The functional role of the alpha-1 adrenergic receptors in cerebral blood flow regulation. Indian J Pharmacol, 2011. 43(5): p. 502-6.

129. Edvinsson, L., et al., Effect of exogenous noradrenaline on local cerebral blood flow after osmotic opening of the blood-brain barrier in the rat. J Physiol, 1978. 274: p. 149-56.

130. Hamner, J.W., et al., Sympathetic control of the cerebral vasculature in humans. Stroke, 2009. 41(1): p. 102-9.

131. Busija, D.W. and C.W. Leffler, Exogenous norepinephrine constricts cerebral arterioles via alpha 2-adrenoceptors in newborn pigs. J Cereb Blood Flow Metab, 1987. 7(2): p. 184-8.

132. Medgett, I.C. and S.Z. Langer, Characterisation of smooth muscle alpha-adrenoceptors and of responses to electrical stimulation in the cat isolated perfused middle cerebral artery. Naunyn Schmiedebergs Arch Pharmacol, 1983. 323(1): p. 24-32. 
133. Usui, H., et al., Differences in contractile responses to electrical stimulation and alphaadrenergic binding sites in isolated cerebral arteries of humans, cows, dogs, and monkeys. $\mathrm{J}$ Cardiovasc Pharmacol, 1985. 7 Suppl 3: p. S47-52.

134. Tsukahara, T., et al., Characterization of alpha adrenoceptors in pial arteries of the bovine brain. Naunyn Schmiedebergs Arch Pharmacol, 1983. 324(2): p. 88-93.

135. Busija, D.W. and C.W. Leffler, Eicosanoid synthesis elicited by norepinephrine in piglet parietal cortex. Brain Res, 1987. 403(2): p. 243-8.

136. Winquist, R.J., R.C. Webb, and D.F. Bohr, Relaxation to transmural nerve stimulation and exogenously added norepinephrine in porcine cerebral vessels. A study utilizing cerebrovascular intrinsic tone. Circ Res, 1982. 51(6): p. 769-76.

137. Wagerle, L.C. and D.W. Busija, Effect of thromboxane A2/endoperoxide antagonist SQ29548 on the contractile response to acetylcholine in newborn piglet cerebral arteries. Circ Res, 1990. 66(3): p. 824-31.

138. Kokubun, S., et al., Differential responses of porcine anterior spinal and middle cerebral arteries to carbon dioxide and pH. Crit Care Med, 2009. 37(3): p. 987-92.

139. del Zoppo, G.J. and T. Mabuchi, Cerebral microvessel responses to focal ischemia. J Cereb Blood Flow Metab, 2003. 23(8): p. 879-94.

140. Roth, S.C., et al., Relation of deranged neonatal cerebral oxidative metabolism with neurodevelopmental outcome and head circumference at 4 years. Dev Med Child Neurol, 1997. 39(11): p. 718-25.

141. Domoki, F., et al., Hydrogen is neuroprotective and preserves cerebrovascular reactivity in asphyxiated newborn pigs. Pediatr Res. 68(5): p. 387-92.

142. Dawson, D.A. and J.M. Hallenbeck, Acute focal ischemia-induced alterations in MAP2 immunostaining: description of temporal changes and utilization as a marker for volumetric assessment of acute brain injury. J Cereb Blood Flow Metab, 1996. 16(1): p. 170-4.

143. Malinak, C. and F.S. Silverstein, Hypoxic-ischemic injury acutely disrupts microtubuleassociated protein 2 immunostaining in neonatal rat brain. Biol Neonate, 1996. 69(4): p. 25767.

144. Gallyas, F., G. Zoltay, and W. Dames, Formation of "dark" (argyrophilic) neurons of various origin proceeds with a common mechanism of biophysical nature (a novel hypothesis). Acta Neuropathol, 1992. 83(5): p. 504-9.

145. Gallyas, F., et al., Golgi-like demonstration of "dark" neurons with an argyrophil III method for experimental neuropathology. Acta Neuropathol, 1990. 79(6): p. 620-8.

146. Gallyas, F., Novel cell-biological ideas deducible from morphological observations on "dark" neurons revisited. Ideggyogy Sz, 2007. 60(5-6): p. 212-22.

147. Iadecola, C. and P.B. Gorelick, The Janus face of cyclooxygenase-2 in ischemic stroke: shifting toward downstream targets. Stroke, 2005. 36(2): p. 182-5.

148. Armstead, W.M., et al., Postischemic generation of superoxide anion by newborn pig brain. Am J Physiol, 1988. 255(2 Pt 2): p. H401-3.

149. Perez-Polo, J.R., C.B. Reilly, and H.C. Rea, Oxygen resuscitation after hypoxia ischemia stimulates prostaglandin pathway in rat cortex. Int J Dev Neurosci, 2011. 29(6): p. 639-44.

150. Degi, R., et al., Effects of anoxic stress on prostaglandin $H$ synthase isoforms in piglet brain. Brain Res Dev Brain Res, 1998. 107(2): p. 265-76.

151. Degi, R., et al., Regional distribution of prostaglandin $H$ synthase-2 and neuronal nitric oxide synthase in piglet brain. Pediatr Res, 1998. 43(5): p. 683-9.

152. Eucker, S.A., et al., Development of a fluorescent microsphere technique for rapid histological determination of cerebral blood flow. Brain Res, 2010. 1326: p. 128-34. 
153. Li, D.Y., et al., Key role for cyclooxygenase-2 in PGE2 and PGF2alpha receptor regulation and cerebral blood flow of the newborn. Am J Physiol, 1997. 273(4 Pt 2): p. R1283-90.

154. Li, D.Y., D.R. Varma, and S. Chemtob, Ontogenic increase in PGE2 and PGF2 alpha receptor density in brain microvessels of pigs. Br J Pharmacol, 1994. 112(1): p. 59-64.

155. Rivkin, M.J., Hypoxic-ischemic brain injury in the term newborn. Neuropathology, clinical aspects, and neuroimaging. Clin Perinatol, 1997. 24(3): p. 607-25.

156. Vannucci, R.C., Mechanisms of perinatal hypoxic-ischemic brain damage. Semin Perinatol, 1993. 17(5): p. 330-7.

157. Degos, V., et al., Neuroprotective strategies for the neonatal brain. Anesth Analg, 2008. 106(6): p. 1670-80.

158. Benders, M.J., et al., Early postnatal allopurinol does not improve short term outcome after severe birth asphyxia. Arch Dis Child Fetal Neonatal Ed, 2006. 91(3): p. F163-5.

159. Torrance, H.L., et al., Maternal allopurinol during fetal hypoxia lowers cord blood levels of the brain injury marker S-100B. Pediatrics, 2009. 124(1): p. 350-7.

160. Kaandorp, J.J., et al., Rapid target allopurinol concentrations in the hypoxic fetus after maternal administration during labour. Arch Dis Child Fetal Neonatal Ed, 2014. 99(2): p. F144-8.

161. Hobbs, C., et al., Xenon and hypothermia combine additively, offering long-term functional and histopathologic neuroprotection after neonatal hypoxia/ischemia. Stroke, 2008. 39(4): p. 1307-13.

162. Thoresen, M., et al., Cooling combined with immediate or delayed xenon inhalation provides equivalent long-term neuroprotection after neonatal hypoxia-ischemia. J Cereb Blood Flow Metab, 2009. 29(4): p. 707-14.

163. David, H.N., et al., Post-ischemic helium provides neuroprotection in rats subjected to middle cerebral artery occlusion-induced ischemia by producing hypothermia. J Cereb Blood Flow Metab, 2009. 29(6): p. 1159-65.

164. Pan, Y., et al., Heliox and oxygen reduce infarct volume in a rat model of focal ischemia. Exp Neurol, 2007. 205(2): p. 587-90.

165. Helmy, M.M., et al., Brain alkalosis causes birth asphyxia seizures, suggesting therapeutic strategy. Ann Neurol, 2011. 69(3): p. 493-500.

166. Lekic, T., et al., Protective effect of hydrogen gas therapy after germinal matrix hemorrhage in neonatal rats. Acta Neurochir Suppl, 2011. 111: p. 237-41.

167. Zhan, Y., et al., Hydrogen gas ameliorates oxidative stress in early brain injury after subarachnoid hemorrhage in rats. Crit Care Med, 2012. 40(4): p. 1291-6.

168. Eckermann, J.M., et al., Potential application of hydrogen in traumatic and surgical brain injury, stroke and neonatal hypoxia-ischemia. Med Gas Res, 2012. 2(1): p. 11.

169. Zheng, X.F., X.J. Sun, and Z.F. Xia, Hydrogen Resuscitation, a New Cytoprotective Approach. Clin Exp Pharmacol Physiol, 2011.

170. Roka, A. and D. Azzopardi, Therapeutic hypothermia for neonatal hypoxic ischaemic encephalopathy. Early Hum Dev, 2010. 86(6): p. 361-7. 